Research Article

\title{
Homogeneously Dispersed Carbon Nanofiber/High- Density Polyethylene Nanocomposite Compatibilized by Dilakylimidazolium Tetrafluoroborate
}

\author{
J. Samuel $\mathbb{D}$, S. Al-Enezi $\mathbb{D}$, A. Al-Banna, and G. Abraham $\mathbb{D}$ \\ Polymeric Product Enhancement and Customization Program, Petroleum Research Center, Kuwait Institute for Scientific Research, \\ P.O. Box 24885, Safat 13109, Kuwait \\ Correspondence should be addressed to J. Samuel; jsamuel@kisr.edu.kw
}

Received 20 February 2019; Revised 13 May 2019; Accepted 5 August 2019; Published 15 September 2019

Academic Editor: Yasuhiko Hayashi

Copyright (๑ 2019 J. Samuel et al. This is an open access article distributed under the Creative Commons Attribution License, which permits unrestricted use, distribution, and reproduction in any medium, provided the original work is properly cited.

\begin{abstract}
High-density polyethylene (HDPE) was used in this study as a matrix for accommodating carbon nanofiber (CNF) along with ionic liquid, to investigate the effect of nanofibers loading on the morphological thermal and rheological properties of the composites. The nanocomposite materials were prepared via melt processing using dilakylimidazolium tetrafluoroborate (ionic liquid) as a compatibilizing agent. The samples blended with imidazolium ionic liquid exhibited higher thermal stability, while DSC analysis showed the clear miscibility of ionic liquid in the HDPE matrix with a single endothermic peak. The influence of CNF (ranging from $0,0.5,1$, and $2 \mathrm{wt} . \%$ ) and ionic liquid concentration on the viscoelastic parameters was investigated. The rheological analysis showed the shear-thinning behavior of the composites. An improvement in the viscoelastic properties was observed as the nanofiber concentration increased. Composites blended with ionic liquid (HDPE/CNF/IL) exhibited slightly lower values of complex viscosity and modulus over the corresponding HDPE/CNF nanocomposites. Therefore, it is also significant that the reduction in melt viscosity is an additional benefit for polymer composite processing as a result of the wetting effect by polymer-ionic liquid combinations.
\end{abstract}

\section{Introduction}

The incorporation of a small amount of nanomaterials such as carbon nanotubes (CNTs) and carbon nanofibers (CNFs) into the polymer matrix significantly improves the electrical properties and mechanical performance of the polymeric materials [1-3] offering great openings for developing multifunctional polymer composite materials, for electromagnetic interference (EMI) shielding electrostatic dissipative (ESD) protection and electrochemical applications [4-6]. However, the overall performance of the polymer nanocomposite mainly depends on the effective dispersion in to the polymer matrix and nanoparticle polymer adhesion [7]. CNFs are different from CNTs in its preparation methods, its unique physical characteristics, and the prospect of low-cost fabrication [8]. CNF requires less purification and readily available with low cost while comparing CNT. The combination of architectural flexibility and high mechanical strength allows the nanofibers to be used in fabricating tough composites for vehicles and aerospace [9]. When combined with polymers, the CNFs can induce improvement in the mechanical properties of the neat polymer and improvement dependent upon the type of polymer matrix, the efficiency of dispersion, and processing history $[10,11]$. Vapor-grown carbon fibers (VGCFs) are the class of CNFs prepared by the catalytic chemical vapor deposition method. The incorporation of high-aspect ratio VGCF in polymer matrix usually exhibits improved physical properties [12] with a conceding in the processing difficulty. Therefore, evaluating the thermal and rheological properties is considered to be an important tool to address these issues related to dispersion behavior. In a number publication, the dispersion and rheological properties of VGCF reinforced polyolefins have been described [13-16]. The dispersion study of VGCF in ionic liquid reported that the aggregated lump of VGCF completely disappeared in the ionic liquid with longer alkyl chain [17]. 
The use of ionic compatibilizer has been reported to be a suitable method to improve CNT dispersion in polystyrene matrix $[18,19]$. Therefore, more related research will be quite interesting to improve dispersions of VGCF with suitable cationic modifications using ionic liquid, a nonflammable, thermally, mechanically, and electrochemically stable salt. Additionally, the presence of long alky groups enables easy melt processing of polymer nanocomposites. The present research looked into dependence of both VGCF and modified VGCF content on physical properties in high-density polyethylene (HDPE), one of the polyolefins most widely used in structural, packaging applications. The objective is to explore the possibility of preparing VGCF/HDPE composites with improved processability. The mechanical behavior of the resultant thermoplastic composites will be further assessed with the help to rheological analysis. From a material design point, not only dispersion and compatibility but also other synergic properties will be addressed to develop polymer nanocomposites with balanced properties.

\section{Materials}

Commercially available CNFs ( $>98 \%$ carbon basis, $D \times L$ $100 \mathrm{~nm} \times 20-200 \mu \mathrm{m}$; produced by a vapor-grown method) were obtained from Sigma-Aldrich, and ionic liquid (IL) and 1-hexadecyl-3-methylimidazolium tetrafluoroborate $>98 \%$ were supplied by IoLiTec.

2.1. Preparation of HDPE/CNF Composites. The overall physical properties of the CNF/HDPE composites are mainly influenced by the dispersion of the CNF in the polymer matrix. Therefore, the dispersion technique plays a key role in the preparation of CNF composites. The most widely used method is melt mixing, due to its easiness and cost effectiveness. In order to obtain a good distribution of CNF in the polymer matrix, a high shear melt mixing is usually essential, although this method will lead to a relatively good dispersion of the CNF. Therefore, the relatively low shear mixing method without sacrificing the dispersion is still a challenge for the preparation of CNF/polymer composites by the melt mixing approach. The use of IL along with CNFs is a promising method to support their dispersion in the polymer matrix. In this process, the compatibility between the IL and $\mathrm{CNF}$ is the key factor, which decides the CNF dispersion and the overall performances of the composites. In the first stage, the CNF powder and HDPE pellets with different filler ratios $(0,0.5,1$, and $2 \mathrm{wt} . \%)$ with and without IL (1 wt.\%) were carefully mixed to ensure an adequate distribution of the particles at the macroscale level. The mixture was then melt-mixed in a laboratory scale twin screw extruder (HAAKE) at a rotor speed of $200 \mathrm{rpm}$ followed by pelletization. Test specimens were prepared using a bench top HAAKE injection molding machine. The temperatures of different zones were $200-220^{\circ} \mathrm{C}$. The neat components of HDPE and HDPE IL were also treated under the same mixing condition for comparison.

2.2. Characterization. The thermal profile (differential scanning calorimetry, DSC) of the HDPE and its nanocomposites was evaluated using DSC 60 A plus Shimadzu with a heating rate of $10^{\circ} \mathrm{C} / \mathrm{min}$ starting from 30 to $220^{\circ} \mathrm{C}$. Thermal degradations were performed in a thermogravimetric analyzer (TGA, TA Discovery). Degradations were performed from 40 to $700^{\circ} \mathrm{C}$, in a nitrogen atmosphere and at a heating rate of $10^{\circ} \mathrm{C} / \mathrm{min}$. The TGA and differential thermogravimetric (DTG) curves were plotted, and the percent weight loss of samples at various temperatures was tabulated. The rheological analysis of CNF/HDPE composites was performed by a hybrid oscillatory rheometer (DHR-3) with a magnetic bearing, force rebalance transducer (FRT), and optical encoder dual reader. The measurements were accomplished using a parallel plate with a geometry gap of $1 \mathrm{~mm}$, and the samples were set between the preheated parallel plates. The influence of frequency and nanofiber concentration was evaluated. The frequency sweep tests were conducted under different frequency conditions $(0.1$ to $100 \mathrm{~Hz})$ with five data points per decade. The measurements were conducted under a constant temperature $\left(200^{\circ} \mathrm{C}\right)$, and an amplitude of deformation of $2 \%$ was applied to obtain the rheological parameters. The parameters corresponding to frequency sweep, such as storage modulus $\left(G^{\prime}\right)$, loss modulus $\left(G^{\prime \prime}\right)$, damping factor ( $\tan$ $\delta)$, and complex viscosity $\left(\eta^{*}\right)$, were measured.

\section{Results and Discussion}

\subsection{Characterization}

3.1.1. FTIR Spectroscopy. The FTIR spectrum of the pure HDPE and HDPE containing IL is presented in Figure 1. The transmittance bands at 2925 and $2864 \mathrm{~cm}^{-1}$ correspond to the $\mathrm{CH}_{2}$ vibration. The band that appeared around $1400 \mathrm{~cm}^{-1}$ was ascribed to $\mathrm{CH}_{2}$ wagging vibration. The C$\mathrm{C}$ band was observed at $1166 \mathrm{~cm}^{-1}$. The FTIR spectra of HDPE/IL blend membranes are depicted in Figure 2. It was detected that most of the characteristic transmittance bands of the pure HDPE was retained by the HDPE-IL blend. For example, the bands at 2926 and $2854 \mathrm{~cm}^{-1}$ were related to the $\mathrm{CH}_{2}$ asymmetric and symmetric vibration. The other major bands ranging from 1242 to $845 \mathrm{~cm}^{-1}$ were also observed. However, compared to pure HDPE, there was additional bands at 1712 and $1743 \mathrm{~cm}^{-1}$ observed for HDPE-IL. The occurrence of the new transmittance band was attributed to the 1-hexadecyl-3-methylimidazolium group present in the IL. It was observed that the IL molecule was well distributed in the HDPE matrix. Figures 2 and 3 show the comparison spectra of various HDPE/CNFs and HDPE/CNF/IL with pure HDPE. The common peaks corresponding to $\mathrm{CH}_{2}$ vibration, C-C bands, C-C-C asymmetrical stretching vibration, and HDPE were observed. Moreover, most of the characteristic transmittance bands of the pure HDPE were retained in the nanocomposite materials. The FTIR overall spectra of the nanocomposites indicated that the IL molecule was also well distributed in the composites uniformly.

3.1.2. Thermogravimetric Analysis. The effect of CNF loading and compatibilization of IL on the thermal behavior of HDPE nanocomposites was analyzed by TGA. The TGA 


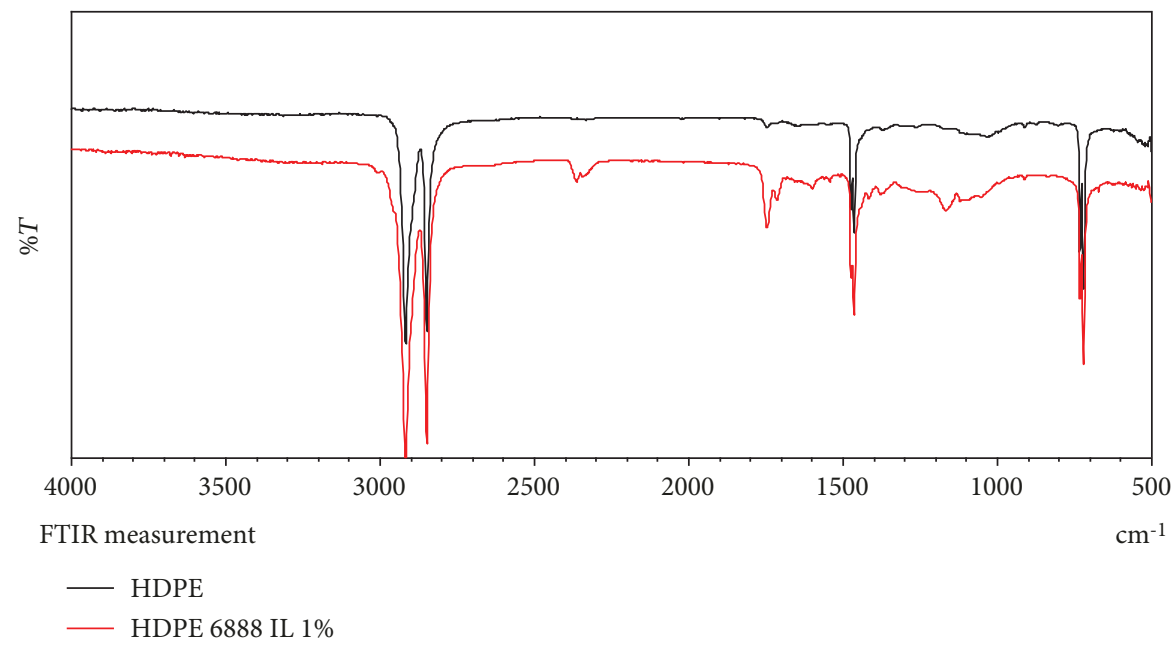

FIGURE 1: FTIR spectra of pure HDPE and HDPE/IL 1\%.

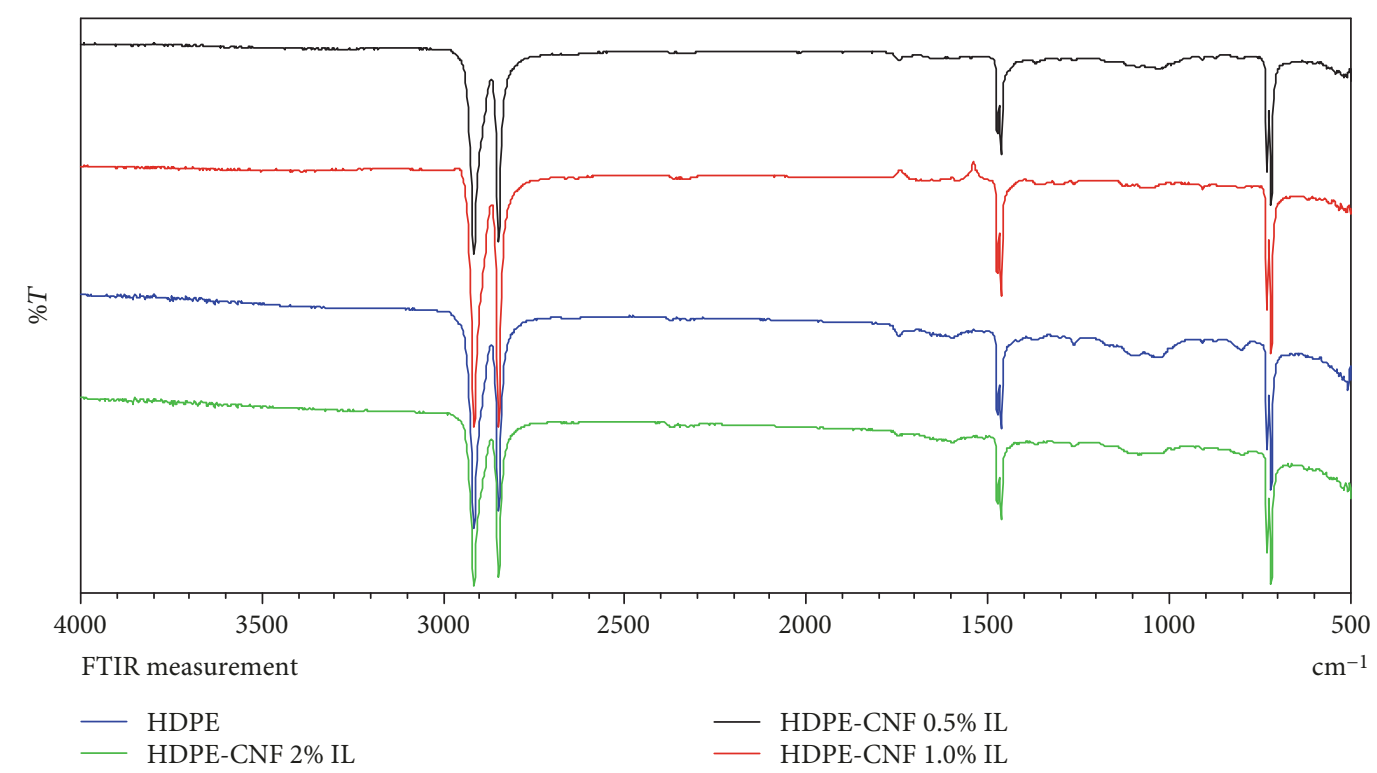

FIGURE 2: FTIR spectra of HDPE/CNF/IL composites.

parameters are stated in Table 1 and traces are shown in Figures 4-8. The thermal stability of the HDPE/CNF nanocomposites was increased by increasing the CNF content. The onset degradation temperature $\left(T_{\text {onset }}\right)$ values of the samples blended with IL showed a considerable improvement. The maximum degradation temperature $\left(T_{d \max }\right)$ was increased by $20^{\circ} \mathrm{C}$ compared to pure HDPE (Table 1 ). This thermal stabilization of the HDPE/CNF/IL composite may be attributed to the improved dispersion of CNFs in the polymer matrix, which increases the interfacial contact between the CNF and the HDPE matrix or an interfacial bonding between filler and matrix. Comparing the results obtained over the thermal degradation showed a clear effect by IL, which was more noticeable during the thermal decomposition process. These results and interpretations are in good correspondence with the results found for the thermal and thermal oxidative decomposition of polymer CNT compos- ites [20,21]. While comparing the derivative curves, it was observed that all of the prepared composites degraded via a single step degradation process similar to the neat HDPE sample. HDPE/IL blend also showed a single step degradation process indicating a uniform solubility of IL in the polymer matrix. However, when thermally stable, imidazole was added to the nanocomposites and the initiation and maximum temperatures were shifted toward higher temperature; this effect is explained by the fine dispersion of the nanofibers. The well-dispersed/distributed nanofibers decrease the polymer permeability to volatile decomposition products. Thus, the addition of the CNF combined with IL reduces the release rate of the volatile byproducts and hence enhances the thermal stability of the nanocomposites.

3.1.3. Differential Scanning Calorimetry. The thermal transition of materials is usually studied by differential scanning 


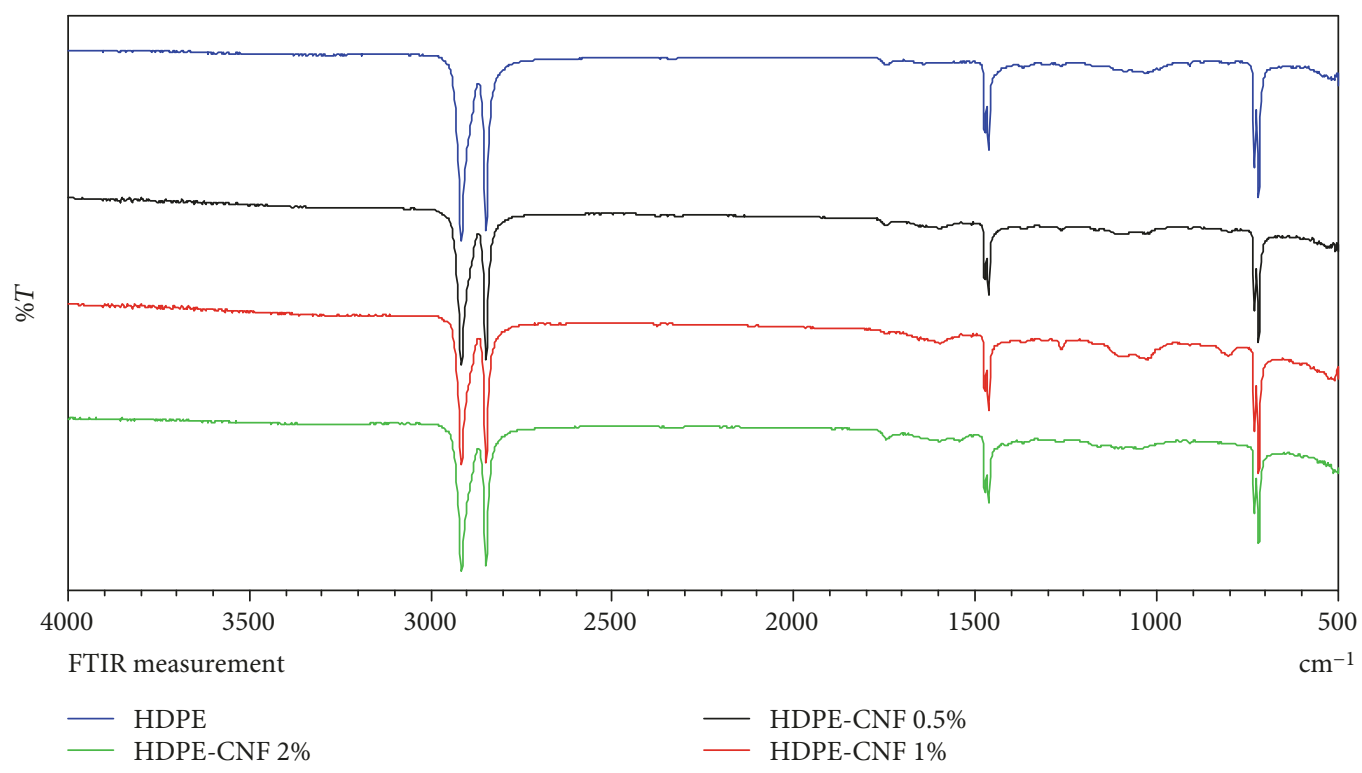

FIGURE 3: FTIR spectra of HDPE/CNF composites.

TABLE 1: TGA and DSC characteristics of HDPE and its nanocomposites.

\begin{tabular}{lccccccc}
\hline Sample & $T_{\text {monset }}\left({ }^{\circ} \mathrm{C}\right)$ & $T_{m}\left({ }^{\circ} \mathrm{C}\right)$ & $\Delta H_{m}(-\mathrm{J} / \mathrm{g})$ & $T_{\text {conset }}\left({ }^{\circ} \mathrm{C}\right)$ & $T_{c}\left({ }^{\circ} \mathrm{C}\right)$ & $\Delta H_{c}(\mathrm{~J} / \mathrm{g})$ & $T_{d \mathrm{max}}\left({ }^{\circ} \mathrm{C}\right)$ \\
\hline HDPE & 123.82 & 132.25 & 139.72 & 117.95 & 114.95 & 138.92 \\
HDPE-IL \% & 122.54 & 131.89 & 156.53 & 118.18 & 114.68 & 140.71 \\
HDPE-CNF 0.5\% & 123.09 & 131.52 & 131.76 & 118.45 & 114.94 & 144.86 \\
HDPE-CNF 1.0\% & 123.21 & 131.86 & 137.76 & 118.25 & 114.35 & 132.67 & 473.24 \\
HDPE-CNF 2.0\% & 122.41 & 132.00 & 147.10 & 118.34 & 114.36 & 137.00 & 476.90 \\
HDPE-CNF 0.5\% IL & 123.96 & 131.96 & 117.61 & 117.95 & 114.50 & 116.82 \\
HDPE-CNF 1.0\% IL & 123.87 & 132.64 & 120.54 & 117.91 & 114.33 & 124.31 \\
HDPE-CNF 2.0\% IL & 124.01 & 132.12 & 123.73 & 118.26 & 113.78 & 126.12 & 481.80 \\
\hline
\end{tabular}

calorimetry (DSC) and also analyzes the heating and cooling cycle to provide phase transition temperature. The heating and cooling curves were recorded for the evaluation of the thermal properties of HDPE/CNF and HDPE/CNF/IL composites (Figures 9 and 10). From the DSC results, it was found that the IL did not exhibit any melting peak, which could be ascribed to the dispersion effect of the long hydrophobic alkyl chain on the HDPE matrix, and the parameters obtained are summarized in Table 1. There was a small decrease in the melting temperature $\left(T_{m}\right)$ of IL blended HDPE and a slight increase upon filler loading. The key challenge in the design of polymer nanocomposites is the monitoring of the distribution of filler particles and other additives for dispersion in the polymer matrix. The crystallization temperature $\left(T_{c}\right)$ for all of the prepared materials showed the same values of neat HDPE, and this can be explained by the well-dispersed CNF without any nucleation or aggregation in the polymer matrix.

3.2. Rheological Properties. Prior to product fabrication, polymers usually undergo production processes that involve thermal and mechanical deformations, which are assumed to be the fundamentals of rheology. In polymer processing opera- tions, an understanding of polymer rheology is the key parameter for the selection of material and process, to provide better service performance. The other factors involved in the rheological behavior of polyolefins' molecular structure are the type of backbone chain and chain branching configuration. The parameter that is preferred is the study on how polymer composition affects the rheological behavior. Polyolefin blended with other polymers, and the addition of fillers and other additives are also of interest. The dependence of rheological behavior on process parameters, such as pressure and temperature, is also an interesting factor. Oscillatory rheological measurements are widely used to study the viscoelastic behavior of polymers and their composites. In the rheometer, the sample is located in a gap between an upper plate and a lower plate. This setup is also called plate-plate geometry.

3.2.1. Amplitude Sweep (=Strain Sweep). During this test, the angular frequency is held constant and the amplitude of the deformation signal or the strain signal is varied, depending on whether the following frequency measurement is supposed to be conducted by deformation control or by strain control. If the amplitude is not too high, the rheological 


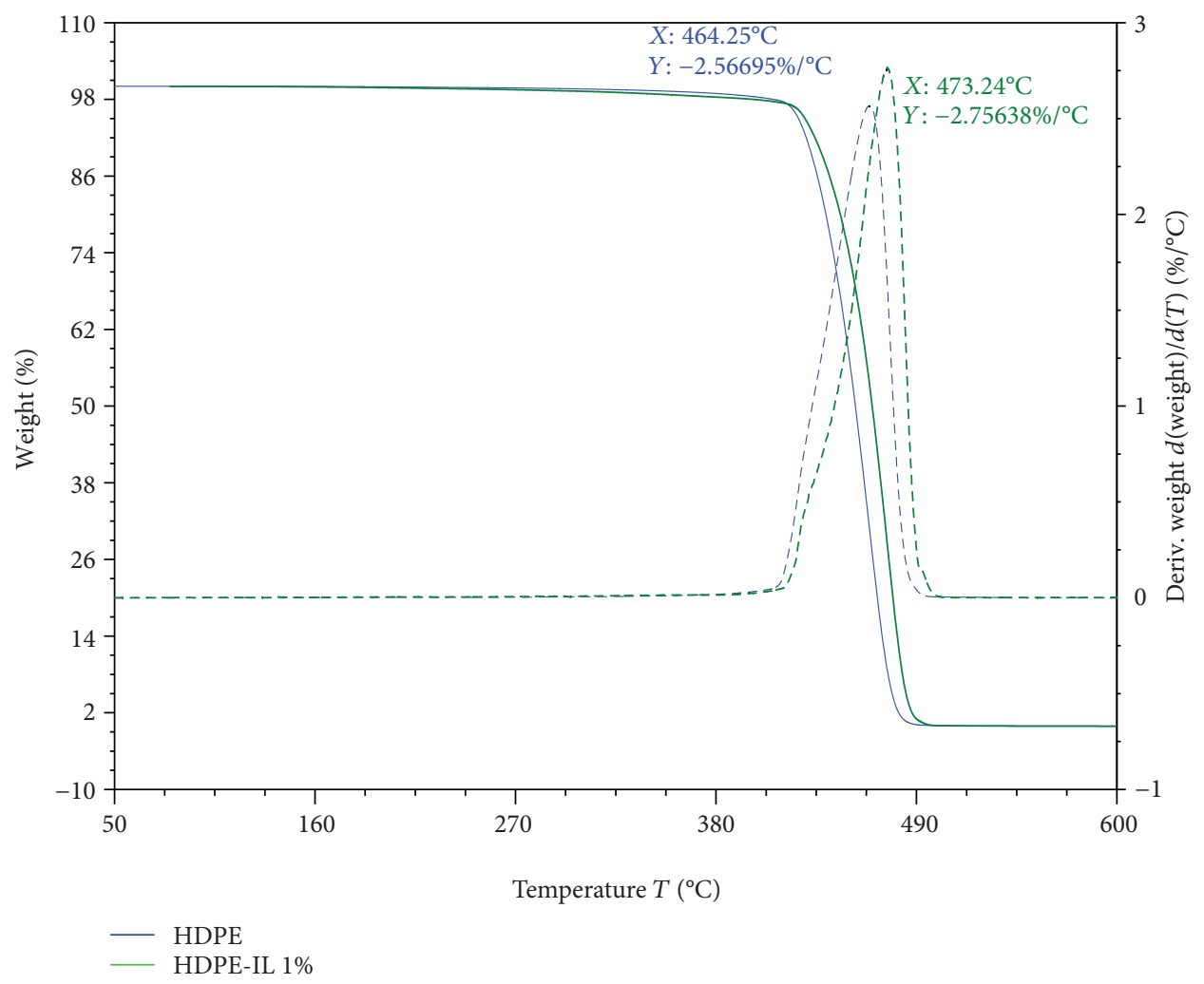

FIgUre 4: TGA and DTG curves of HDPE and HDPE/IL.

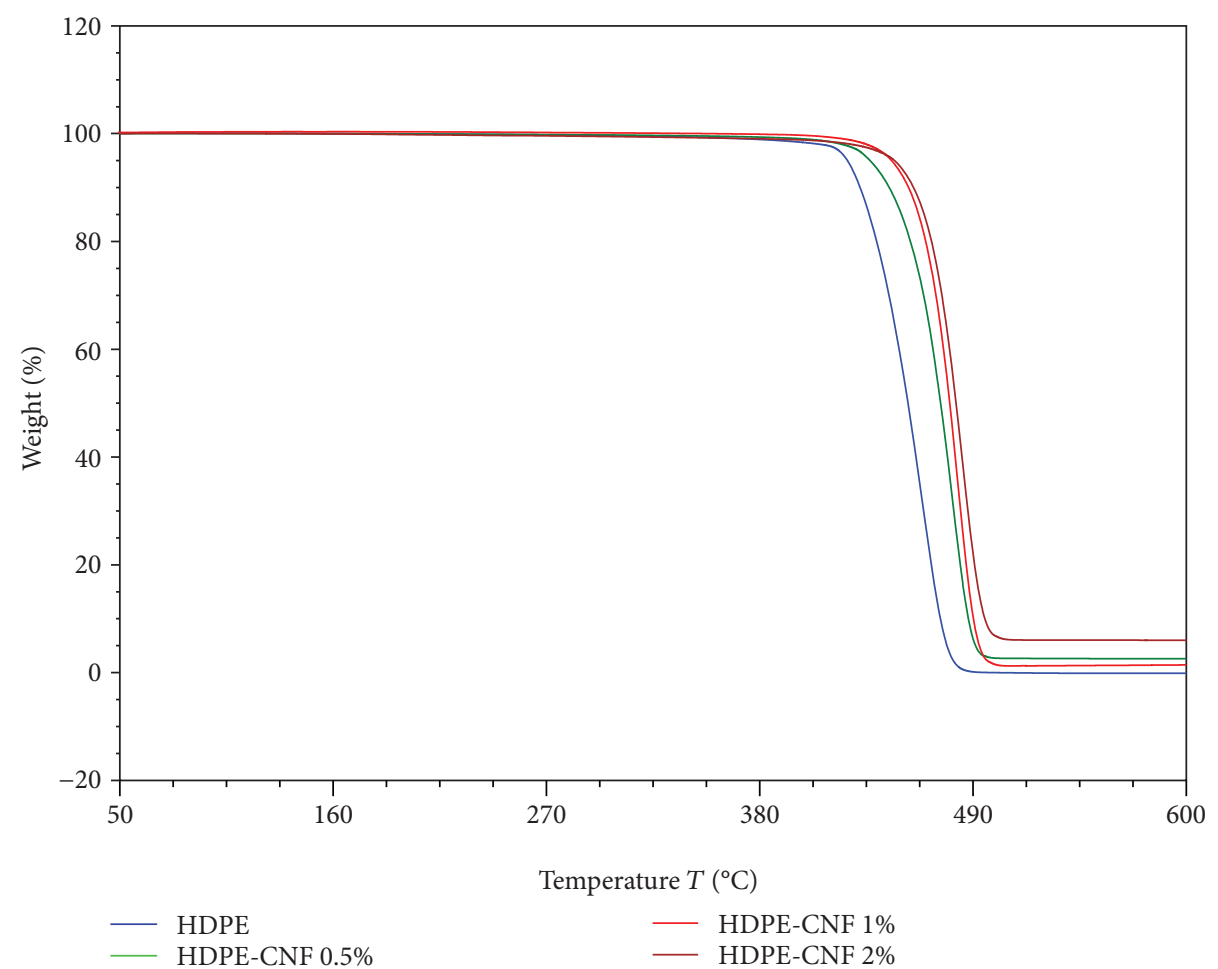

FIgURE 5: TGA curves of HDPE and HDPE/CNF composites. 


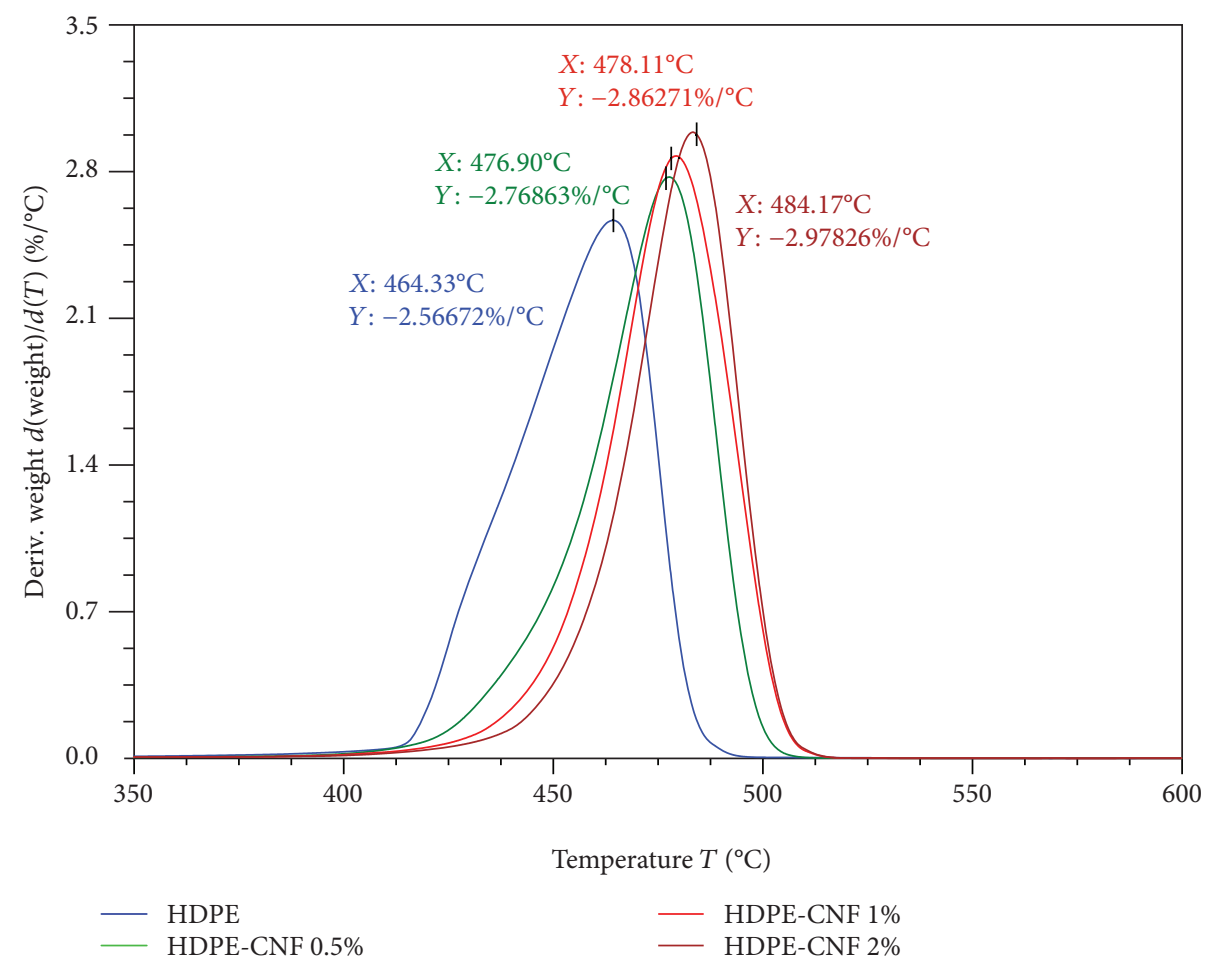

FIGURE 6: DTG curves of HDPE and HDPE/CNF composites.

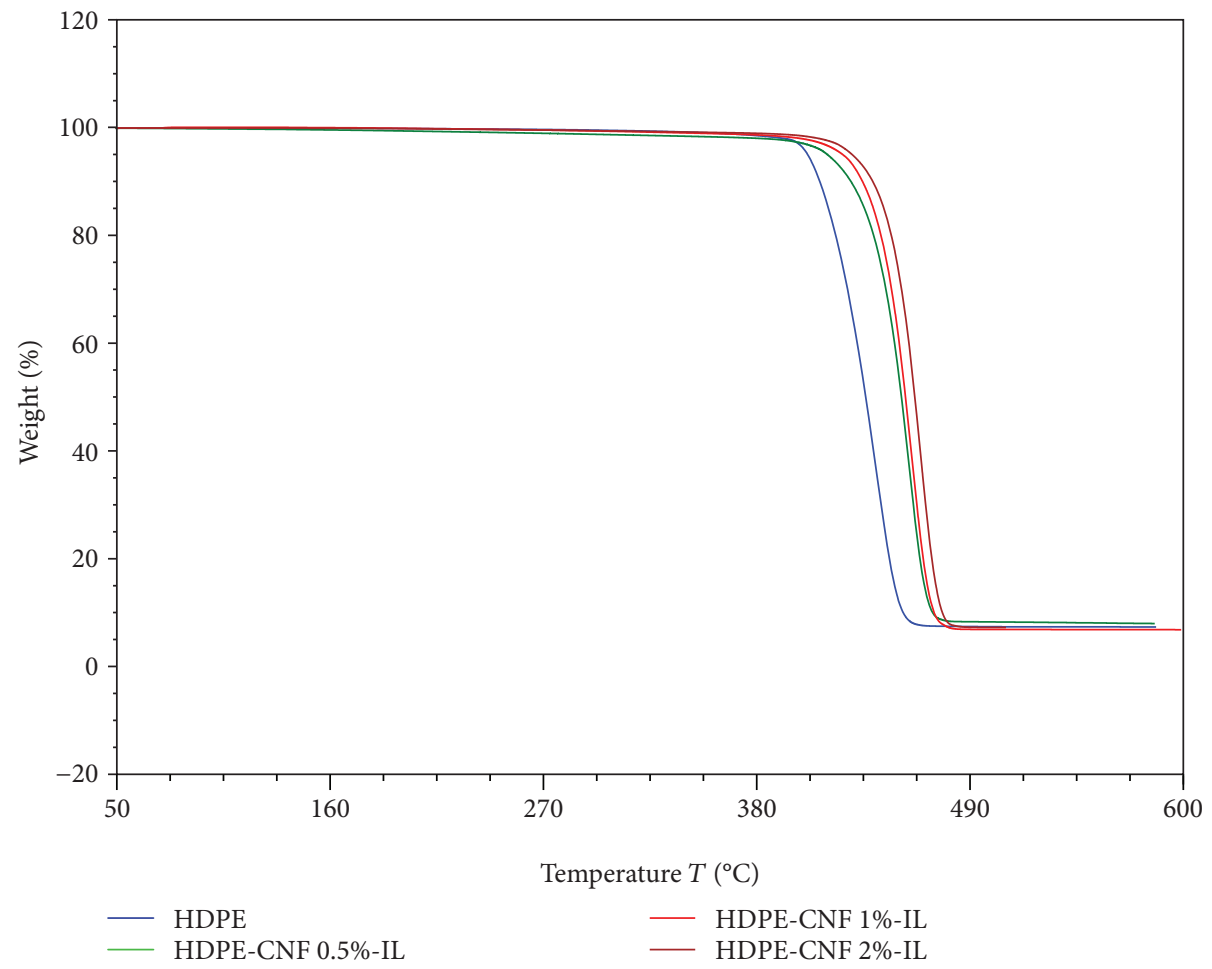

FIGURE 7: TGA curves of HDPE and HDPE/CNF/IL composites.

parameters, such as $G^{\prime}$ and $G^{\prime \prime}$, never show any dependence on the amplitude. This measurement range is called the region of linear viscoelasticity. In this range, the idle state of the material is not disturbed. Starting from a specific amplitude value, the $G^{\prime}$ and $G^{\prime \prime}$ decrease with increasing amplitude. In this range, the laws of nonlinear viscoelasticity are 


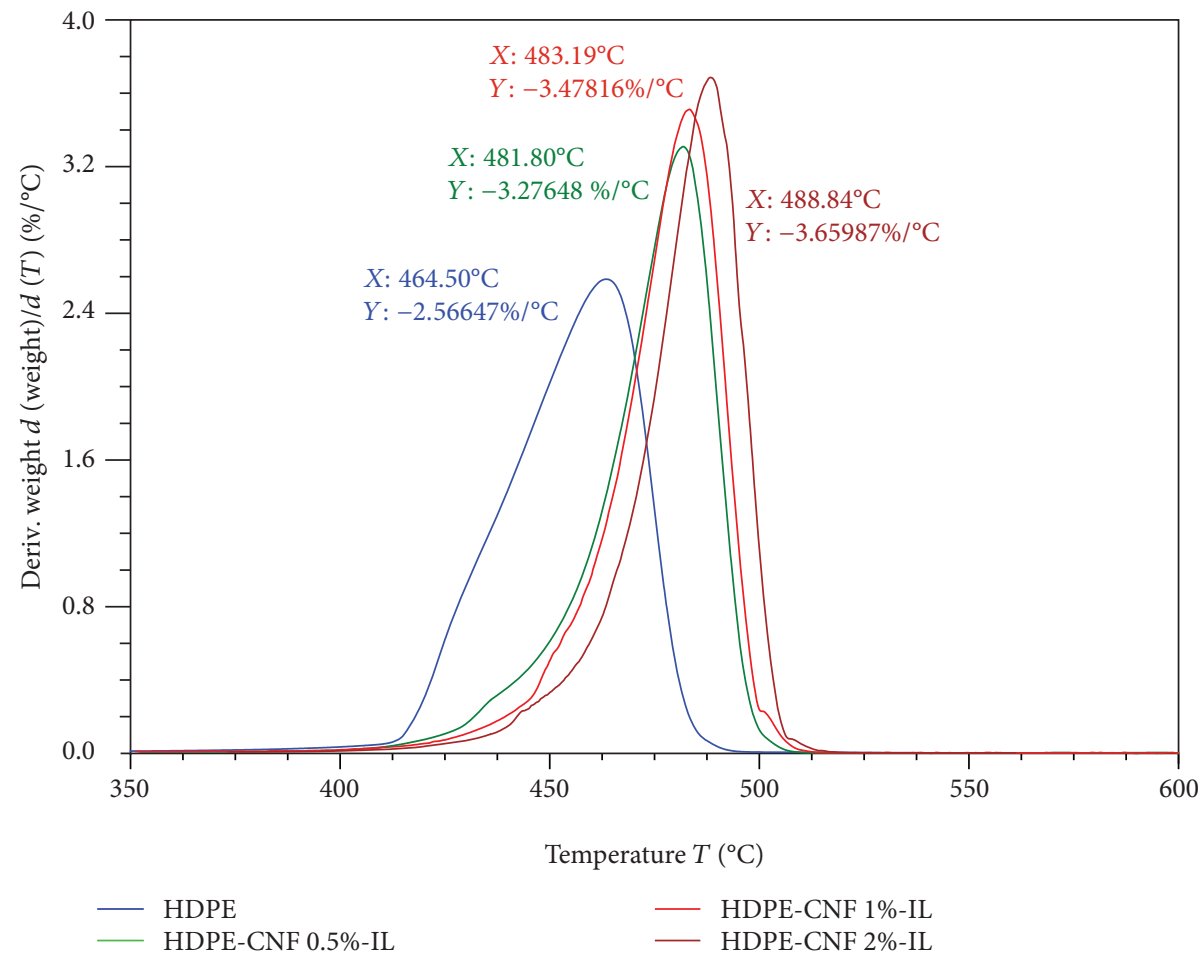

Figure 8: DTG curves of HDPE and HDPE/CNF/IL composites.

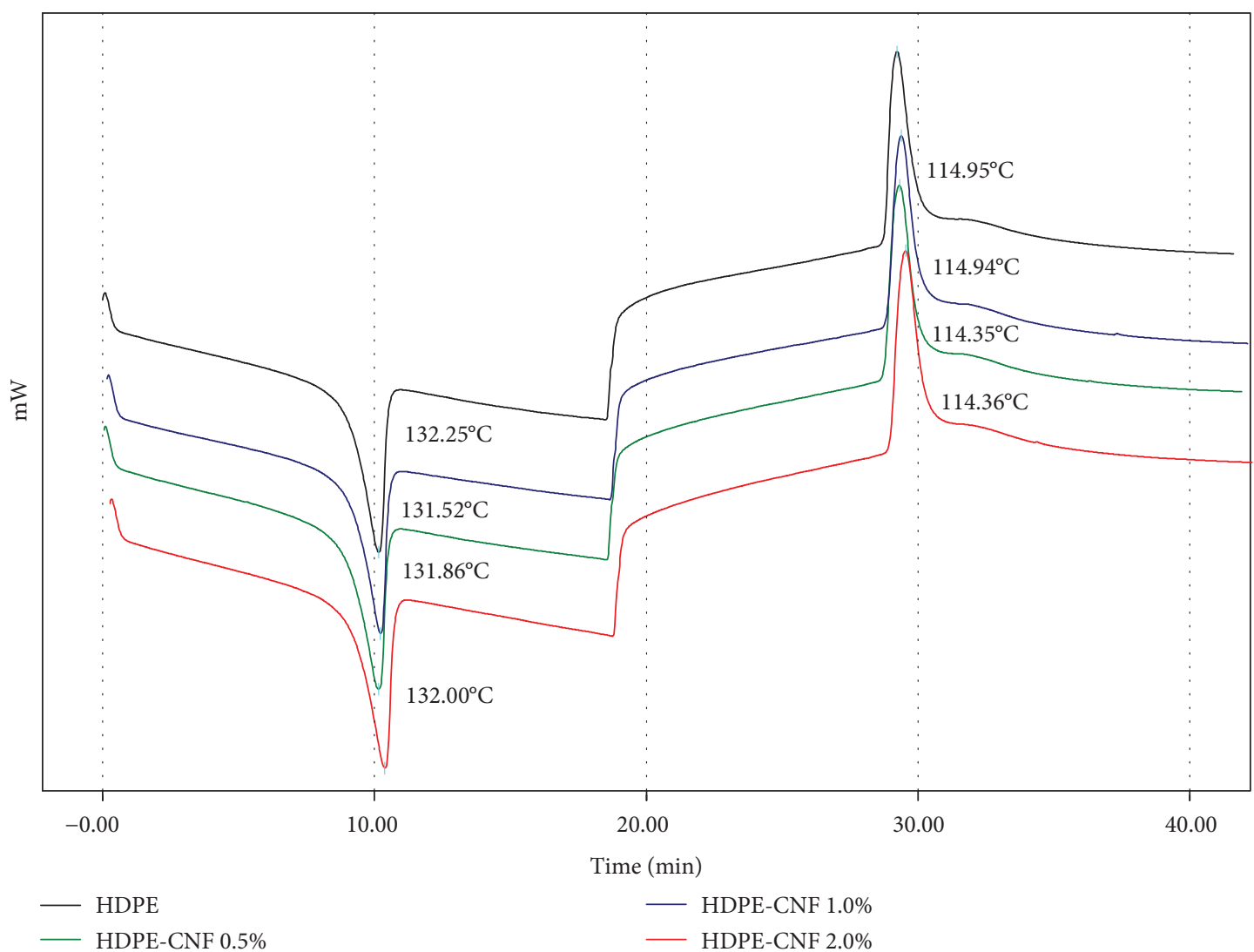

Figure 9: DSC heating and cooling plots of HDPE and HDPE/CNF composites. 


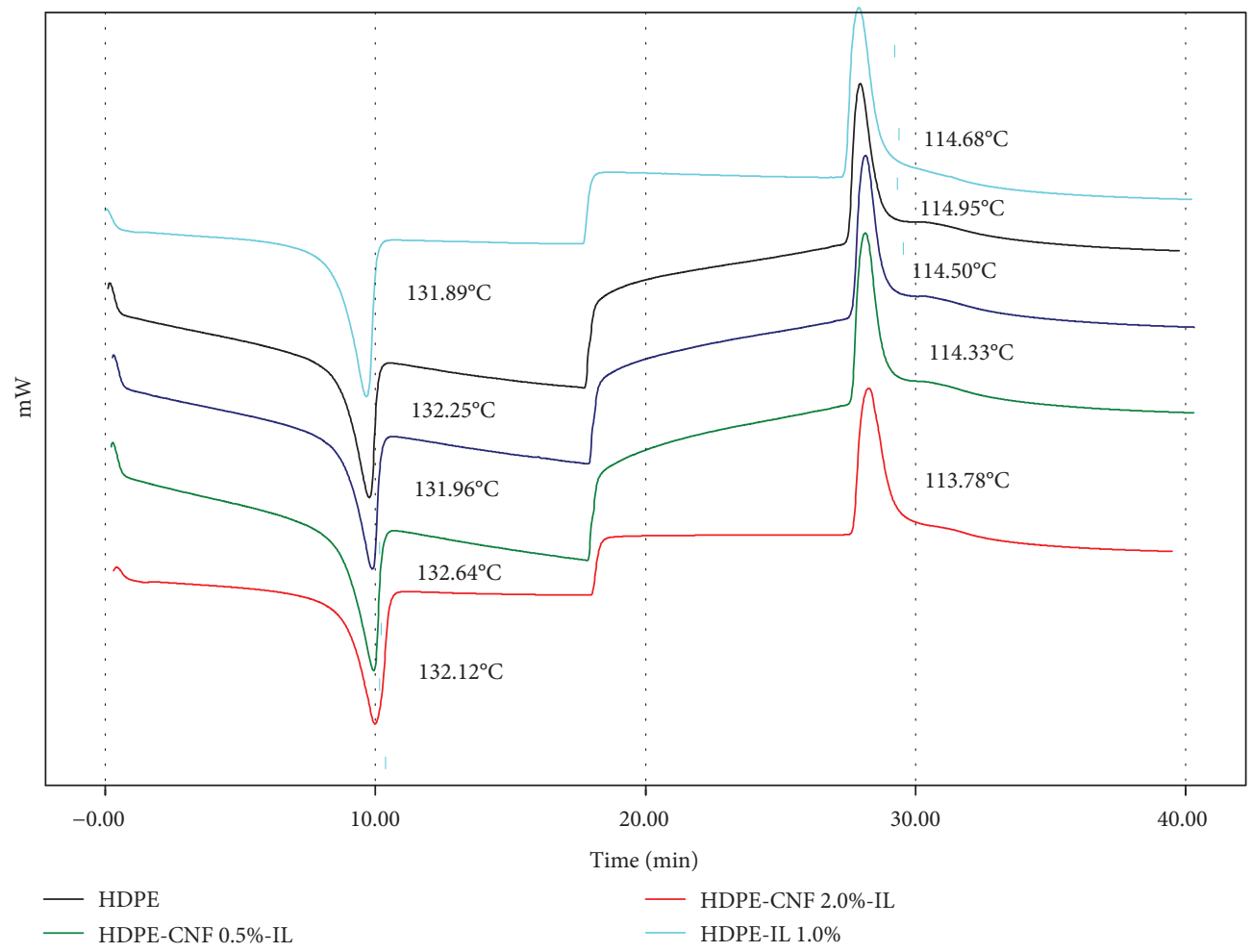

— HDPE-CNF 1.0\%-IL

FIGURE 10: DSC heating and cooling plots of HDPE-IL and HDPE/CNF/IL composites.

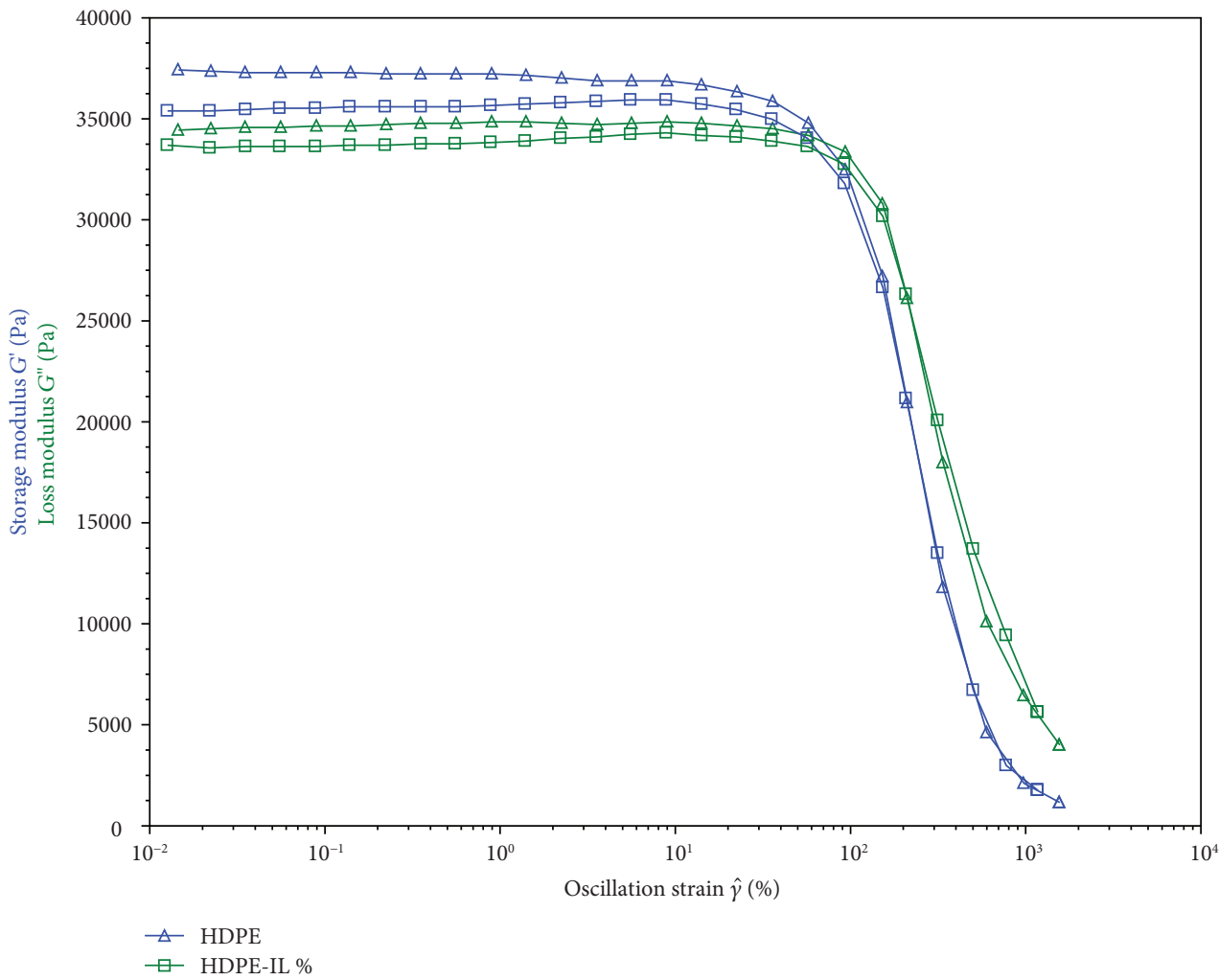

Figure 11: Results of the amplitude sweep test of HDPE and HDPE/IL. 


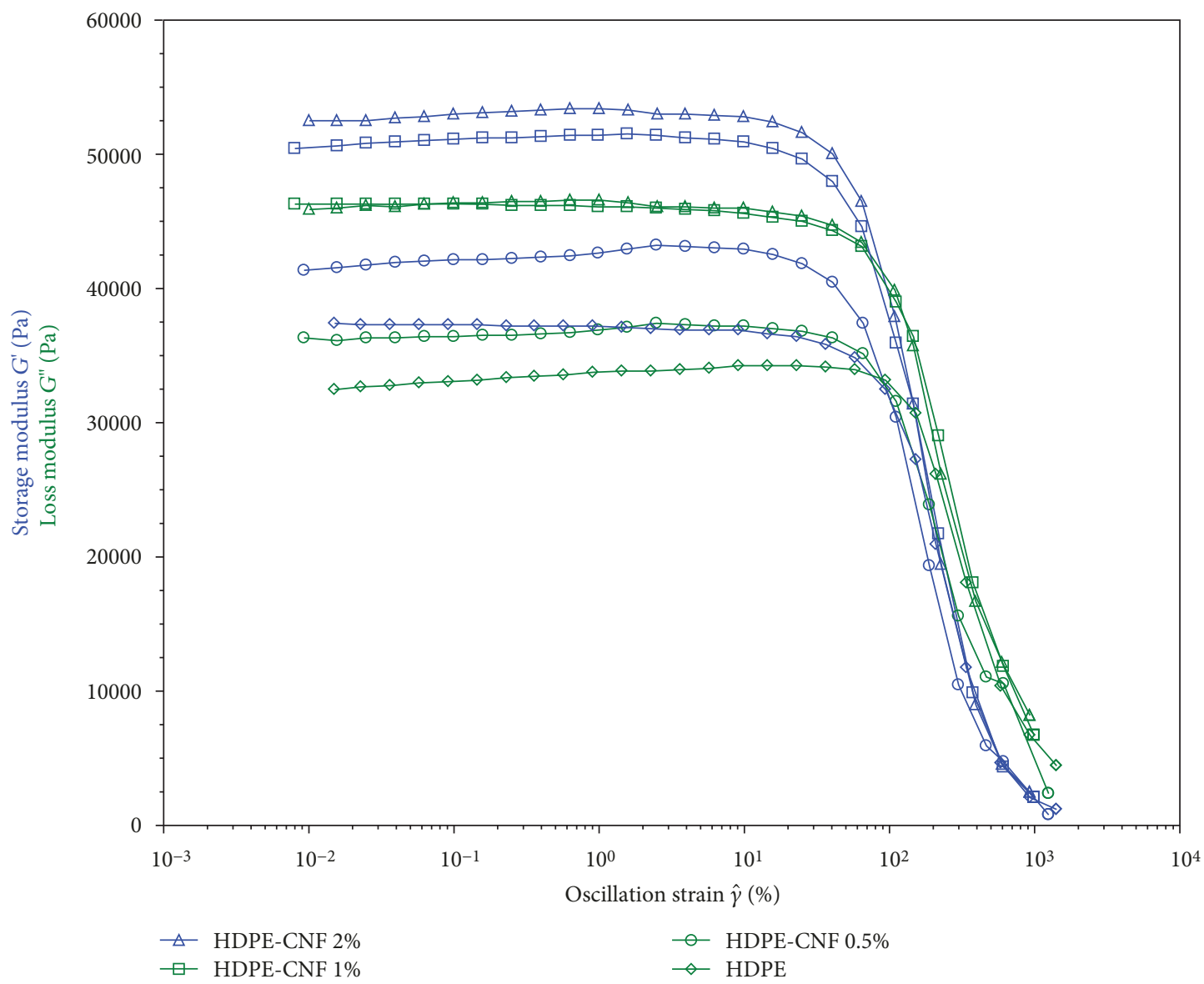

Figure 12: Results of the amplitude sweep test of HDPE and HDPE/CNF.

applicable; the idle state of the sample is disturbed. Strain sweep tests were conducted at $200^{\circ} \mathrm{C}$ in nitrogen atmosphere with a constant frequency of $1 \mathrm{~Hz}$ and in the strain range of 0.01 to $100 \%$. As illustrated in Figures 11-13, the response of all samples does not depend on the strain (both $G^{\prime}$ and $G^{\prime \prime}$ exhibit a constant plateau), and the behavior is well within the linear viscoelastic region.

However, the plateau region never shortens with IL and CNF contents in the HDPE matrix. It can also be seen that $G^{\prime}$ is dominating over $G^{\prime \prime}$ for all composites analyzed, indicating that the overall behavior is dominated by elastic solid-like segmental frictions. As the filler content increases, the gap between $G^{\prime}$ and $G^{\prime \prime}$ values increases, showing that viscous behavior becomes less pronounced and a tendency to a regular shift from viscoelastic liquid-like to solid-like behavior is exhibited.

Moreover, the nanotube network can be considered to be an elastic structure, and the strength of such a network can be related to the cohesion energy. Fundamentally, the linear domain is limited to a very low deformation, where the storage modulus $G^{\prime}$ is constant. The values for $G^{\prime}$ and $G^{\prime \prime}$ in the linear regime are considered as a characteristic elastic time. The cohesive energy is the characteristic of the network strength, and its rise is a direct impact of the enhancement of CNF-HDPE interactions. The effect of nanotube concen- tration was also examined in the same manner. The cohesion energy increases with nanotube content indicating that the nanotube interactions are stronger at a higher CNF loading level.

3.2.2. Frequency Sweep. The viscoelastic properties of polymers and their composites typically play an important role in the material processing. The parameters obtained in this study describe the fundamental behavior of HDPE and HDPE filled with CNF and IL in processing. Within the frequency test, the angular frequency $\omega$ is varied, whereas the deformation amplitude $\gamma_{0}$ is held constant. Concerning an optimum in signal to noise ratio, the highest possible deformation or strain amplitude is chosen from the rheograms of the amplitude tests, which is just in the linear viscoelastic area. Commonly, storage modulus $G^{\prime}(\omega)$, loss modulus $G^{\prime \prime}(\omega)$, and the absolute value of complex viscosity $\left(\eta^{*}\right)$ were measured and drawn against angular frequency $\omega$ in a double logarithmic reference frame, because the rheological parameters change with radial frequency over several orders of magnitude. The angular frequency dependence of shear storage modulus $\left(G^{\prime}\right)$ and shear loss modulus $\left(G^{\prime \prime}\right)$ and complex viscosity $\left(\eta^{*}\right)$ at $200^{\circ} \mathrm{C}$ are plotted in Figures 14 and 15. Complex viscosity was observed to increase with the increase in concentration of the CNF content. In a fiber-reinforced 


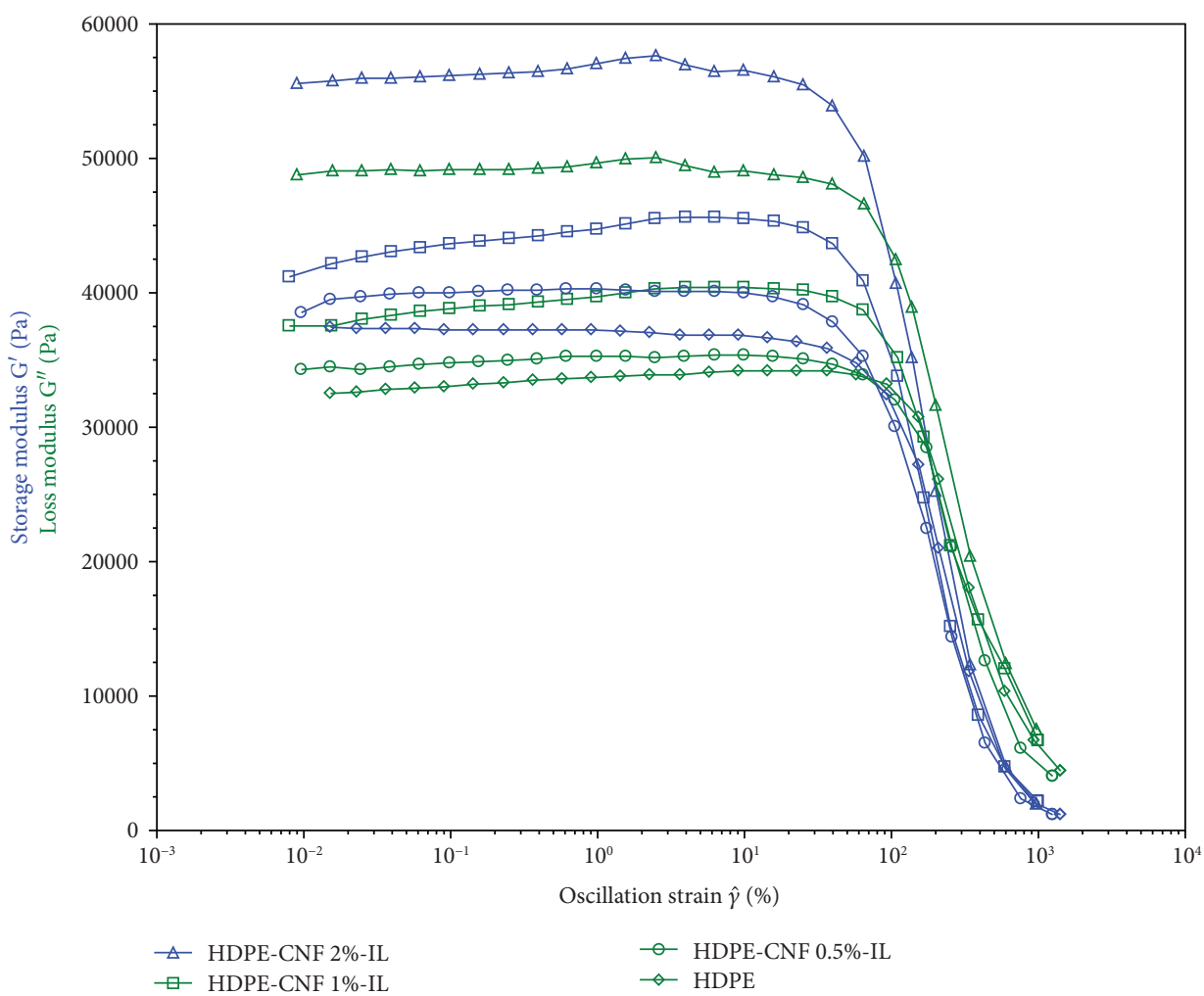

FIGURE 13: Results of the amplitude sweep test of HDPE and HDPE/CNF/IL composites.

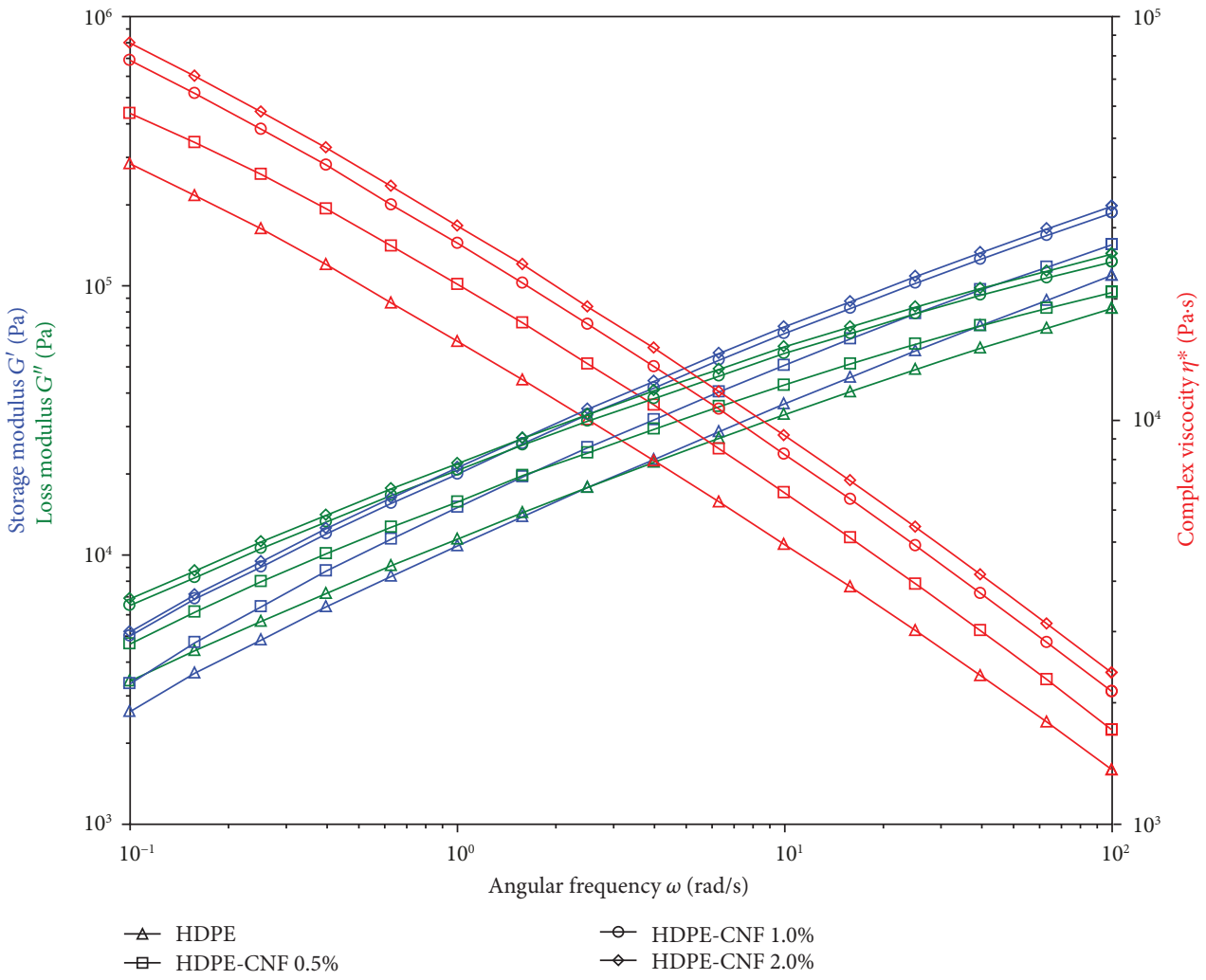

FIGURE 14: Variation of storage, loss modulus, and complex viscosity with angular frequency of HDPE/CNF nanocomposites. 


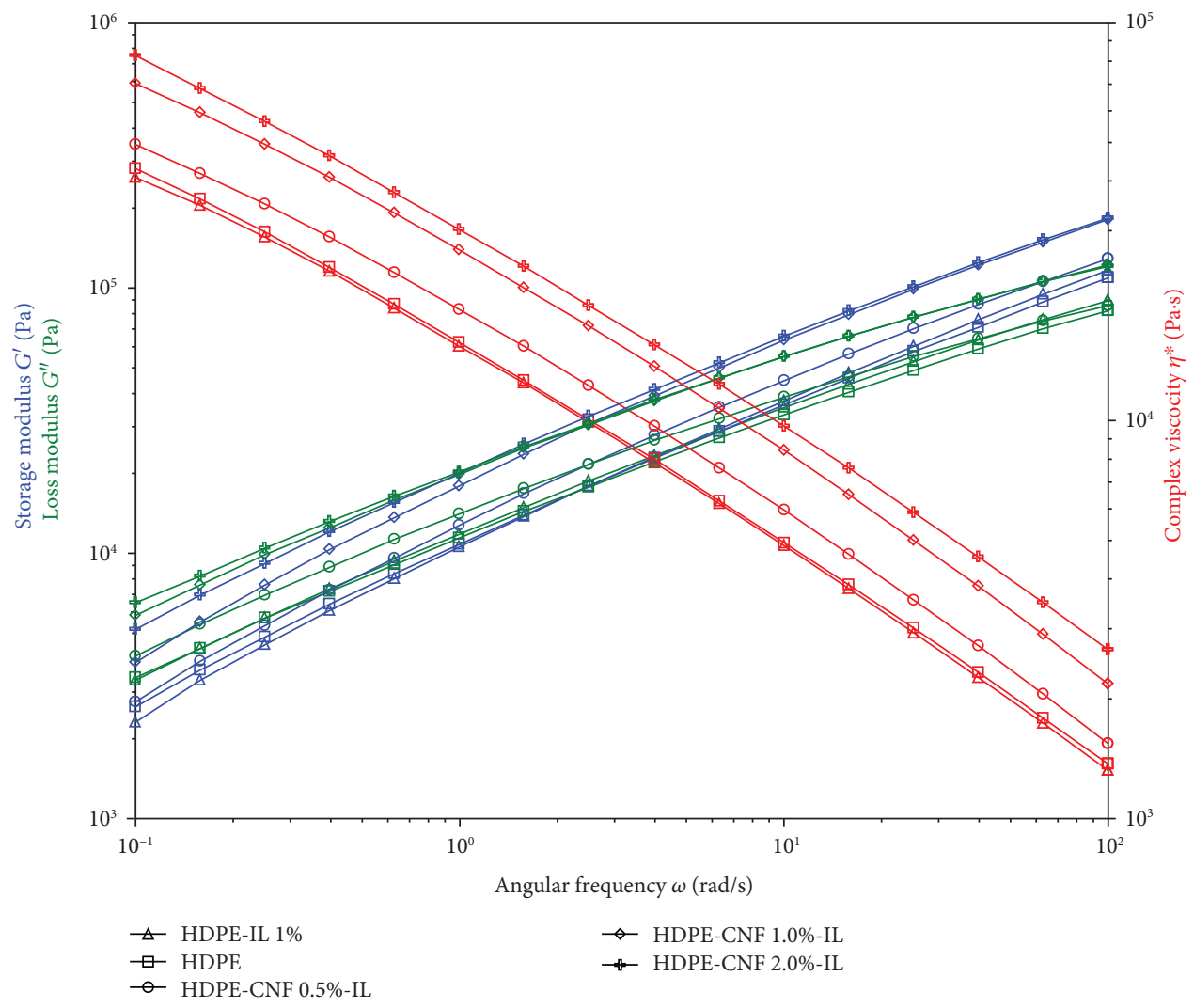

FIGURE 15: Variation of storage, loss modulus, and complex viscosity with angular frequency of HDPE/CNF/IL nanocomposites.

TABLE 2: Rheological parameters of HDPE and its nanocomposites.

\begin{tabular}{|c|c|c|c|c|c|c|}
\hline \multirow{2}{*}{ Sample } & \multirow{2}{*}{ Crossover modulus $(\mathrm{Pa})$} & \multirow{2}{*}{ Crossover frequency $(\mathrm{rad} / \mathrm{s})(\mathrm{Hz})$} & \multicolumn{4}{|c|}{ Complex viscosity $(\mathrm{Pa} \cdot \mathrm{s})$} \\
\hline & & & $0.1(\mathrm{rad} / \mathrm{s})$ & $1(\mathrm{rad} / \mathrm{s})$ & $10(\mathrm{rad} / \mathrm{s})$ & $100(\mathrm{rad} / \mathrm{s})$ \\
\hline HDPE & 17352 & $2.37(0.378)$ & 43075 & 15718 & 4939 & 1366 \\
\hline HDPE-IL $1 \%$ & 25215 & $4.69(0.746)$ & 40434 & 15315 & 4883 & 1318 \\
\hline HDPE-CNF 0.5\% & 20568 & $1.75(0.279)$ & 57491 & 21745 & 6638 & 1711 \\
\hline HDPE-CNF $1.0 \%$ & 23835 & $1.36(0.217)$ & 78122 & 27412 & 8271 & 2124 \\
\hline HDPE-CNF $2.0 \%$ & 26298 & $1.48(0.236)$ & 86103 & 30348 & 9178 & 2361 \\
\hline HDPE-CNF 0.5\% IL & 21624 & $1.53(0.244)$ & 49457 & 19014 & 5940 & 1545 \\
\hline HDPE-CNF $1.0 \%$ IL & 30489 & $1.49(0.397)$ & 70123 & 26809 & 8387 & 2182 \\
\hline HDPE-CNF $2.0 \%$ IL & 25038 & $1.58(0.189)$ & 82346 & 30203 & 9672 & 2648 \\
\hline
\end{tabular}

polymer, the presence of fibrous fillers perturbs the melt flow and obstructs the mobility of chain segments in flow, and therefore, the viscosity of the filled polymer system increases $[6,9]$. The complex viscosity of the CNF filled HDPE composites decreases with the increasing frequency. The presence of IL tends to produce a small decrease in viscosity, which follows closely with the neat HDPE, which is attributed to the plasticizing effect of IL [14]. The complex viscosity values at high frequencies, for filled and neat HDPE samples, showed a tendency to merge together. The values $\eta^{*}$ (Table 2) showed a reduction in complex viscosity for filled systems compared to the IL compatibilized filled systems. Therefore, the reduction in melt viscosity is a supplementary benefit for polymer composite processing. Figure 15 shows that the neat HDPE and CNF/HDPE/IL systems display viscous behavior at low frequencies $\left(G^{\prime \prime}>G^{\prime}\right)$ and an elastic behavior at high frequencies $\left(G^{\prime}>G^{\prime \prime}\right)$. The crossover modulus values decreased with increasing filler loading. The crossover frequency and modulus values showed a different viscous behavior for the filled systems. The incorporation of CNF fillers in the HDPE matrix induces restrictions in the molecular chain mobility to exhibit pronounced elastic properties compared to the neat HDPE.

3.2.3. Damping. The mechanism in which the composite material absorbs and disperses energy is expressed by $\tan \delta$. 


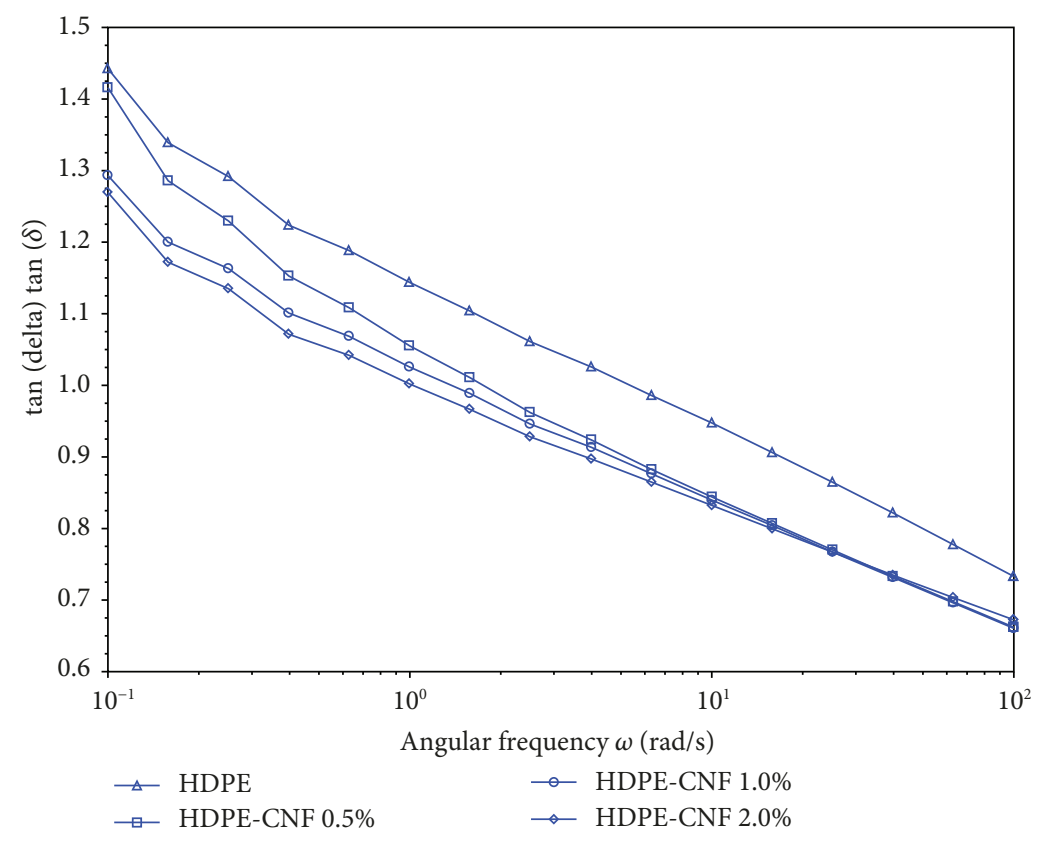

FIGURE 16: Variation of dissipation factor with the angular frequency of HDPE/CNF composites.

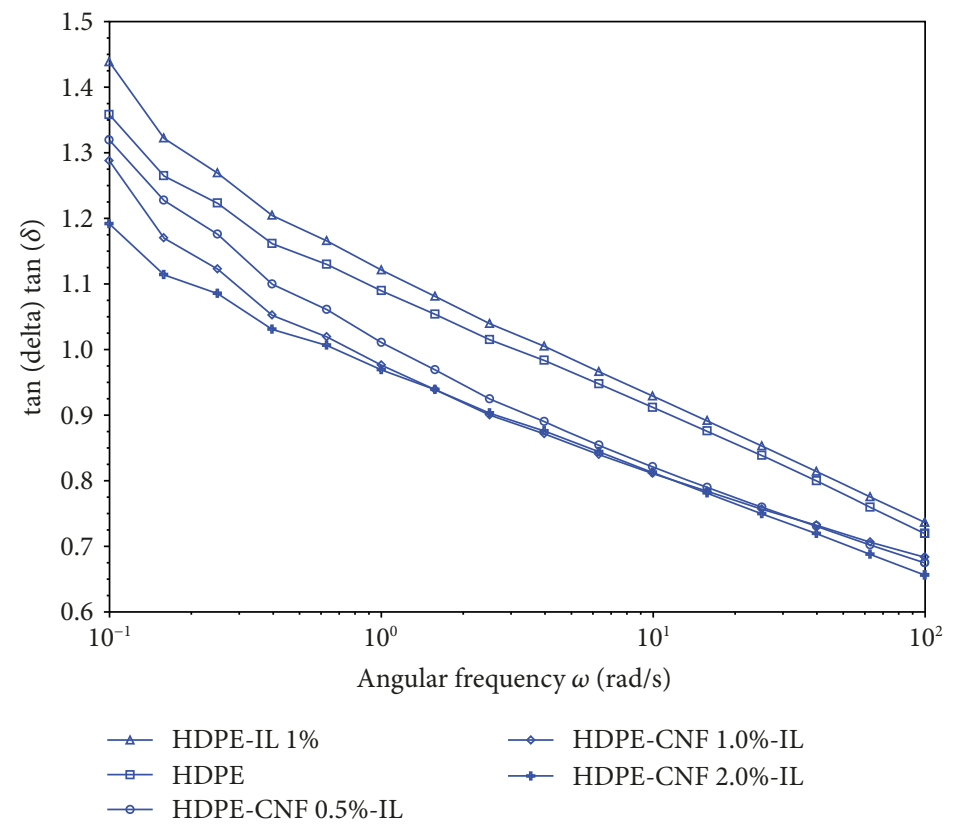

FIGURE 17: Variation of dissipation factor with the angular frequency of HDPE/CNF/IL composites.

The $\tan \delta\left(\tan \delta=G^{\prime \prime} / G^{\prime}\right)$ is calculated and plotted in Figures 16 and 17. $\tan \delta$ also gives the information of how efficiently the nanocomposites lose energy to molecular rearrangements and internal friction, the relation between frequencies. In this composite system, $\tan \delta$ decreases with the incorporation of $\mathrm{CNF}$, which is mainly attributed to the interfacial interaction between CNF and HDPE matrix, and consequently, the energy dissipation in the form of heat energy is minimum. The HDPE blended with IL showed a slight higher value than the CNF filled system. This is due to the lack of friction between the polymer chains due to the wetting effect by the IL. The wetting effect was also observed in the IL compatibilized CNF/HDPE system, which was mainly due to the existence of effective interfacial bonding between CNF and IL so that the viscoelastic energy dissipation in the composite was limited. Moreover, if there is a lack of the interfacial bonding, applied energy will be dissipated in the form of heat due to the interaction between the fiber and the matrix. At a higher fiber content, the fiber-fiber friction increases; therefore, the damping of the composite reaches even a higher value than that of the low fiber concentration composites. 


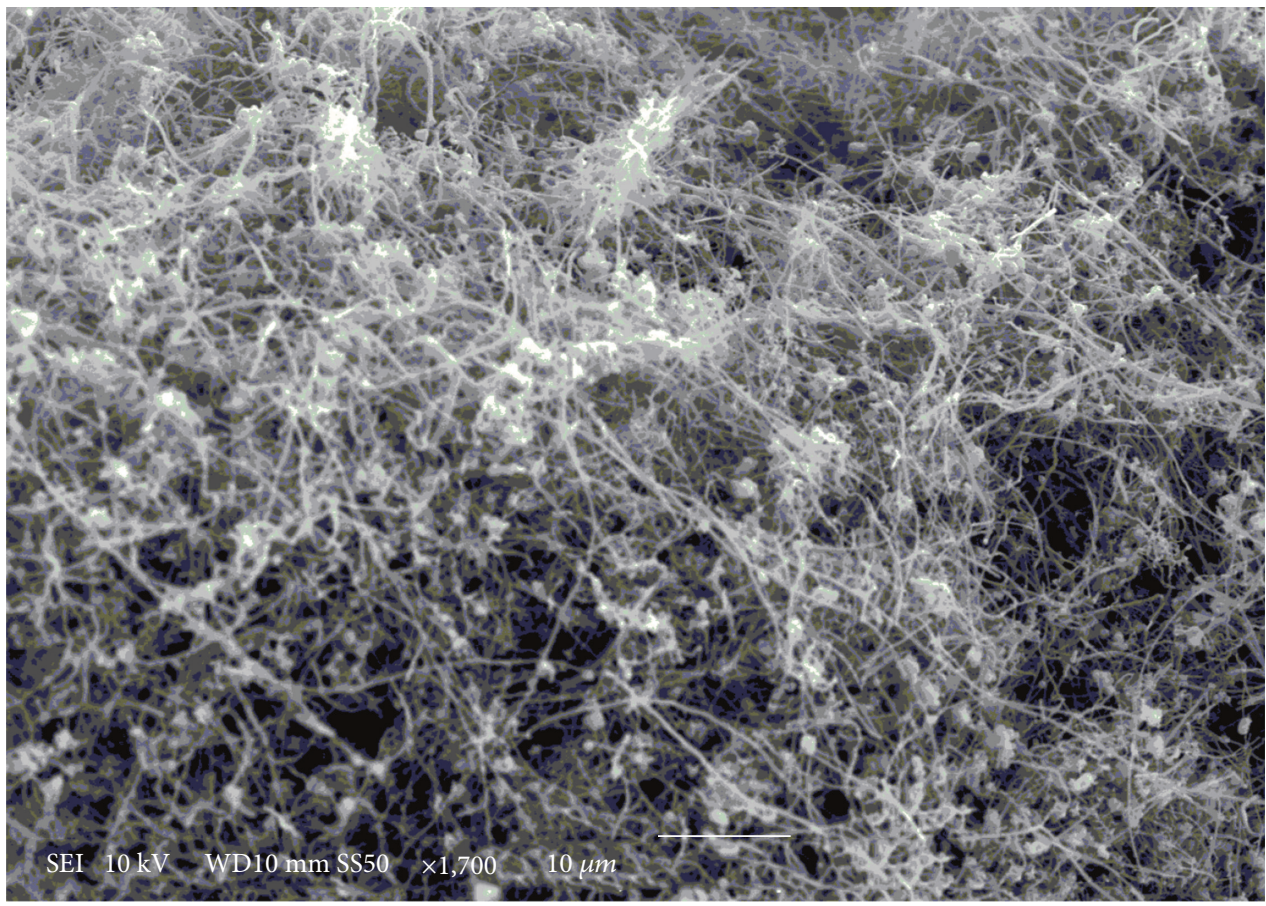

FIgURE 18: SEM image of carbon nanofiber.

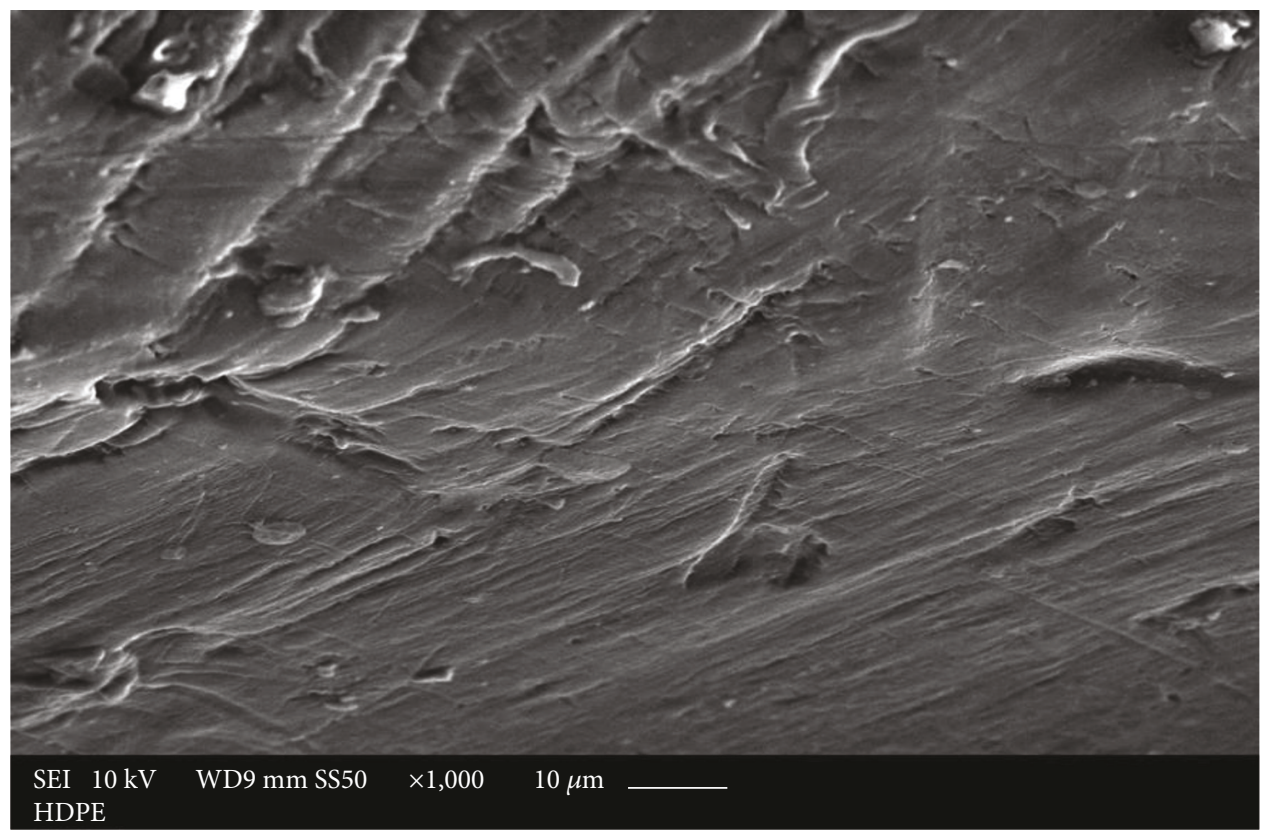

Figure 19: SEM image of pure HDPE.

3.3. Morphology. The Scanning Electron Microscopic (SEM) technique was used to explore the surface morphologies of HDPE and HDPE/CNF composite samples. The surface morphology of CNFs is depicted in Figure 18. CNFs are entangled fibrous structures with $D \times L 100 \mathrm{~nm} \times$ $20-200 \mu \mathrm{m}$. The fractured surface of HDPE exhibits face morphologies seen with the surface roughness (Figure 19). The morphology of the HDPE/CNF and HDPE/CNF/IL (Figures 20 and 21) materials mainly depends on the condi- tions under which the melt mixing was carried out. The addition of IL into polymeric materials improves the plasticization and thereby wetting.

Adding proper amount of IL into the polymer melt could improve the fine dispersion of nanofibers and thereby decrease the aggregation behavior of nanofibers within the matrix. In HDPE/CNFs, entangled CNF bundles were found. But in the HDPE/CNF/IL, CNFs untangled to form better dispersion through an interaction between IL and CNF. 

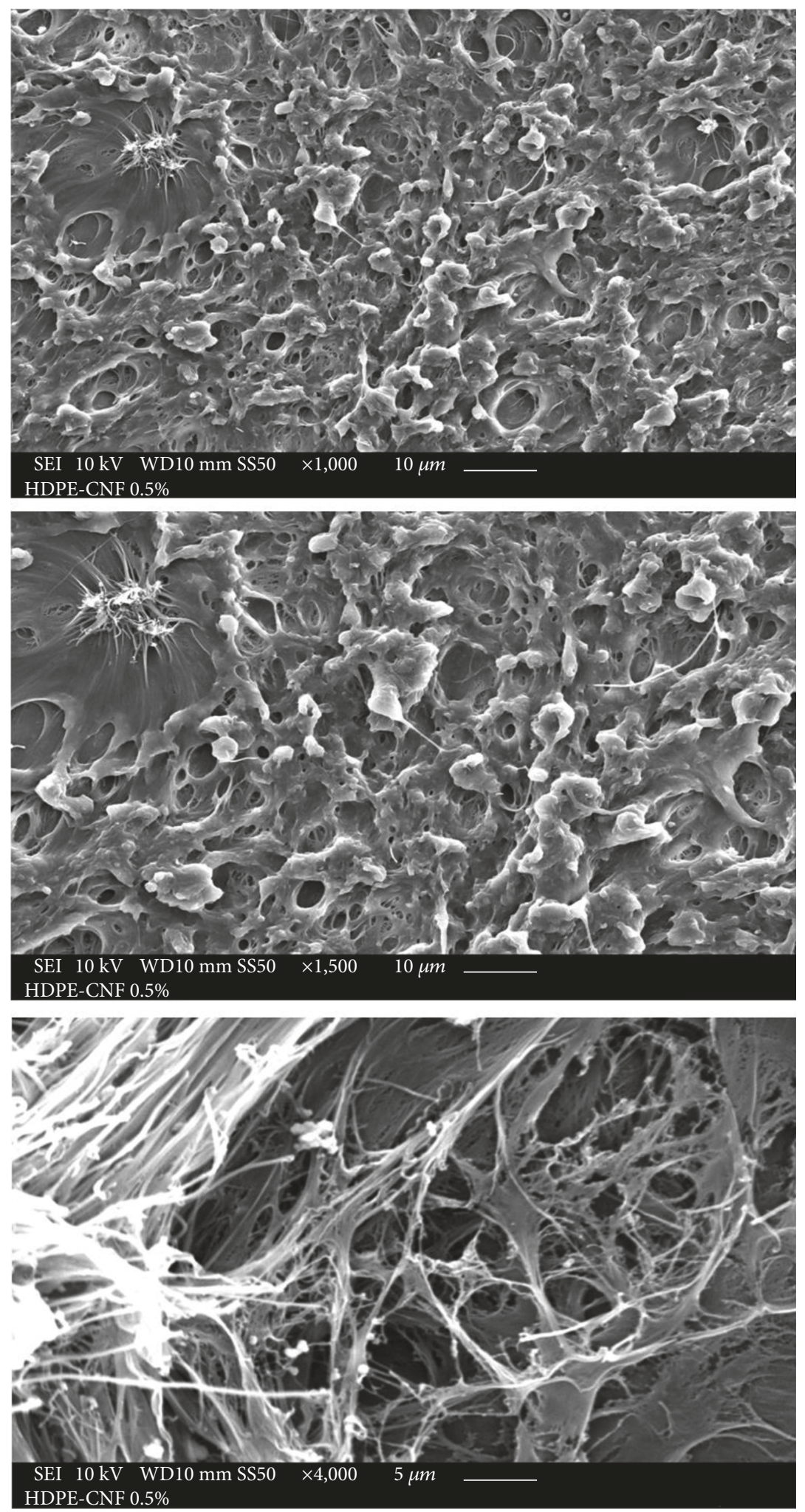

FIGURE 20: SEM images of HDPE/CNF 0.5\% at different magnifications.

The ILs, which possesses a cationic site, can effectively armor the strong $\pi-\pi$ stacking among CNFs and thus evidently disperse the CNFs. The retaining of SWCNTs' intrinsic property and the higher SWCNT content make the ionic liquids ideal media for the study and application of SWCNTs. Most of the experimental results indicated that the ILs interact with CNFs through the cation- $\pi$ interaction present in the HDPE/CNF/IL system. 

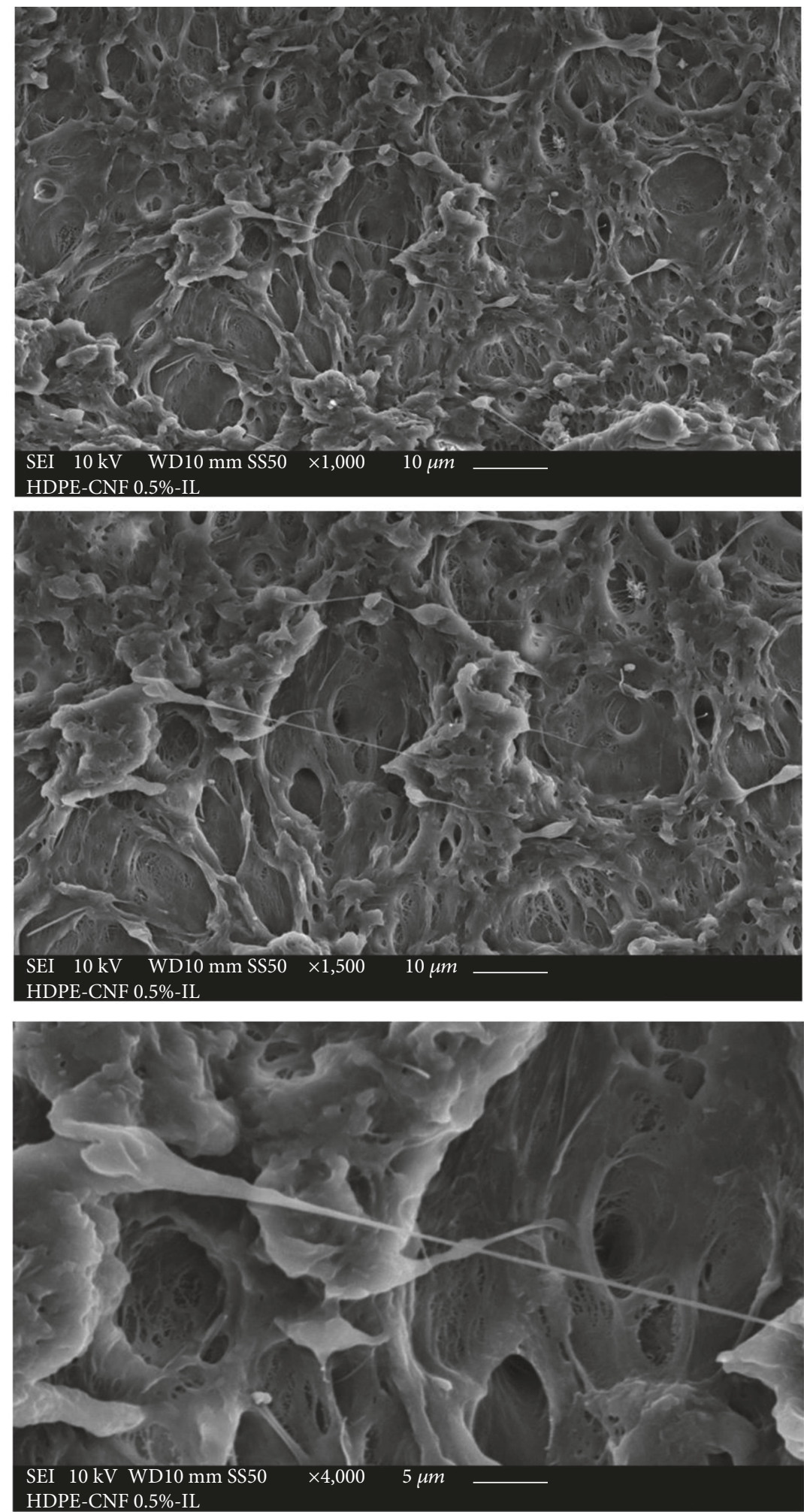

Figure 21: SEM images of HDPE/CNF 0.5\%-IL at different magnifications.

\section{Conclusion}

HDPE/CNFs have been prepared via melt processing using 1-hexadecyl-3-methylimidazolium tetrafluoroborate (IL) as a compatibilizing agent. The FTIR spectra of the nanocom- posites indicated that the IL molecules were well distributed in the composites. TGA results showed that composite samples blended with imidazolium IL exhibited higher thermal stability. DSC analysis clearly indicated the miscibility of IL in the HDPE matrix and showed a single 
endothermic peak corresponding to the HDPE matrix. Melt rheological properties of $\mathrm{CNF} / \mathrm{HDPE}$ and $\mathrm{CNF} / \mathrm{HDPE} / \mathrm{IL}$ were reported as a function of CNF loading. The complex viscosity of the composites was found to increase with fiber loading due to an increased interference of the melt flow. The measurements also showed that IL incorporated HDPE and CNF/HDPE systems exhibited lower complex viscosity than the unfilled HDPE, and this could be the molecular motion due to the availability of greater free volume and weaker intermolecular interactions. The composites showed stronger shear thinning behavior with an increase in fiber concentration at higher frequencies, where the addition of IL to the HDPE brought a variation in the processing behavior.

\section{Data Availability}

No data were used to support this study.

\section{Conflicts of Interest}

There is no conflict of interests regarding the publication of this manuscript.

\section{Acknowledgments}

The authors thank KISR for funding (PC024K) and the technical support of PPEC center.

\section{References}

[1] T. Fukushima, A. Kosaka, Y. Ishimura et al., "Molecular ordering of organic molten salts triggered by single-walled carbon nanotubes," Science, vol. 300, no. 5628, pp. 2072-2074, 2003.

[2] T. Takahashi, K. Yonetake, K. Koyama, and T. Kikuchi, "Polycarbonate crystallization by vapor-grown carbon fiber with and without magnetic field," Macromolecular Rapid Communications, vol. 24, no. 13, pp. 763-767, 2003.

[3] L. Zhang, X. Wang, R. Li, Q. Li, P. D. Bradford, and Y. Zhu, "Microcombing enables high-performance carbon nanotube composites," Composites Science and Technology, vol. 123, pp. 92-98, 2016.

[4] M. H. Al-Saleh and U. Sundararaj, "A review of vapor grown carbon nanofiber/polymer conductive composites," Carbon, vol. 47, no. 1, pp. 2-22, 2009.

[5] N. Terasawa and K. Asaka, "High-performance polymer actuators based on an iridium oxide and vapor-grown carbon nanofibers combining electrostatic double-layer and faradaic capacitor mechanisms," Sensors and Actuators B: Chemical, vol. 240, pp. 536-542, 2017.

[6] F. Geng, A. Yuan, and J. Xu, "Synthesis and electrochemical performance of a coaxial VGCF@ $\mathrm{ZnMnO}_{3}$ nanocomposite as a high-capacity anode material for lithium-ion batteries," Electrochimica Acta, vol. 216, pp. 376-385, 2016.

[7] K. Xiao, L. Zhang, and I. Zarudi, "Mechanical and rheological properties of carbon nanotube reinforced polyethylene composites," Composites Science and Technology, vol. 67, no. 2, pp. 177-182, 2007.

[8] N. M. Rodriguez, "A review of catalytically grown carbon nanofibers," Journal of Materials Research, vol. 8, no. 12, pp. 3233-3250, 1993.
[9] G. G. Tibbetts, "Vapor-grown carbon fibers: status and prospects," Carbon, vol. 27, no. 5, pp. 745-747, 1989.

[10] Y. Hu, T. Liu, J. L. Ding, and W. H. Zhong, "Behavior of high density polyethylene and its nanocomposites under static and dynamic compression loadings," Polymer Composites, vol. 34, no. 3, pp. 417-425, 2013.

[11] J. Gou, S. O'Braint, H. Gu, and G. Song, "Damping Augmentation of Nanocomposites Using Carbon Nanofiber Paper," Journal of Nanomaterials, vol. 2006, Article ID 32803, 7 pages, 2006.

[12] E. Ivan'kova, I. Kasatkin, O. Moskalyuk, V. Yudin, and J. M. Kenny, "Structural aspects of mechanical properties of iPP-based composites. I. Composite iPP fibers with VGCF nanofiller," Journal of Applied Polymer Science, vol. 132, no. 16, 2015.

[13] B. Li, W. Wood, L. Baker, G. Sui, C. Leer, and W. H. Zhong, "Effectual dispersion of carbon nanofibers in polyetherimide composites and their mechanical and tribological properties," Polymer Engineering and Science, vol. 50, no. 10, pp. 19141922, 2010.

[14] J. Samuel, S. Al-Enezi, and A. Al-Banna, "Preparation of carbon nanofiber reinforced HDPE using dialkylimidazolium as a dispersing agent: effect on thermal and rheological properties," International Journal of Chemical and Materials Engineering, vol. 12, no. 9, pp. 475-479, 2018.

[15] K. Lozano and E. V. Barrera, "Nanofiber-reinforced thermoplastic composites. I. Thermoanalytical and mechanical analyses," Journal of Applied Polymer Science, vol. 79, no. 1, pp. 125-133, 2001.

[16] K. Lozano, S. Yang, and R. E. Jones, "Nanofiber toughened polyethylene composites," Carbon, vol. 42, no. 11, pp. 2329 2331, 2004.

[17] J. Samuel, H. Awano, T. Takahashi, K. Yonetake, and K. Koyama, "Dispersion of vapor-grown carbon fibers in ionic liquid," TANSO, vol. 2006, no. 223, pp. 188-190, 2006.

[18] M. Mičušík, M. Omastová, J. Pionteck, C. Pandis, E. Logakis, and P. Pissis, "Influence of surface treatment of multiwall carbon nanotubes on the properties of polypropylene/carbon nanotubes nanocomposites," Polymers for Advanced Technologies, vol. 22, no. 1, pp. 38-47, 2011.

[19] S. Bellayer, J. W. Gilman, N. Eidelman et al., "Preparation of homogeneously dispersed multiwalled carbon nanotube/polystyrene nanocomposites via melt extrusion using trialkyl imidazolium compatibilizer," Advanced Functional Materials, vol. 15, no. 6, pp. 910-916, 2005.

[20] J. Li, L. Tong, Z. Fang, A. Gu, and Z. Xu, "Thermal degradation behavior of multi-walled carbon nanotubes/polyamide 6 composites," Polymer Degradation and Stability, vol. 91, no. 9, pp. 2046-2052, 2006.

[21] T. Kashiwagi, E. Grulke, J. Hilding, R. Harris, W. Awad, and J. Douglas, "Thermal degradation and flammability properties of poly(propylene)/carbon nanotube composites," Macromolecular Rapid Communications, vol. 23, no. 13, pp. 761-765, 2002. 


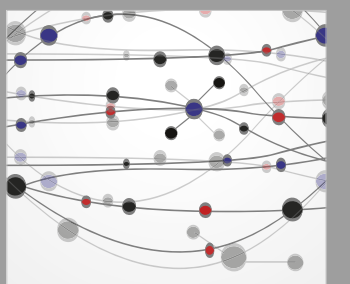

The Scientific World Journal
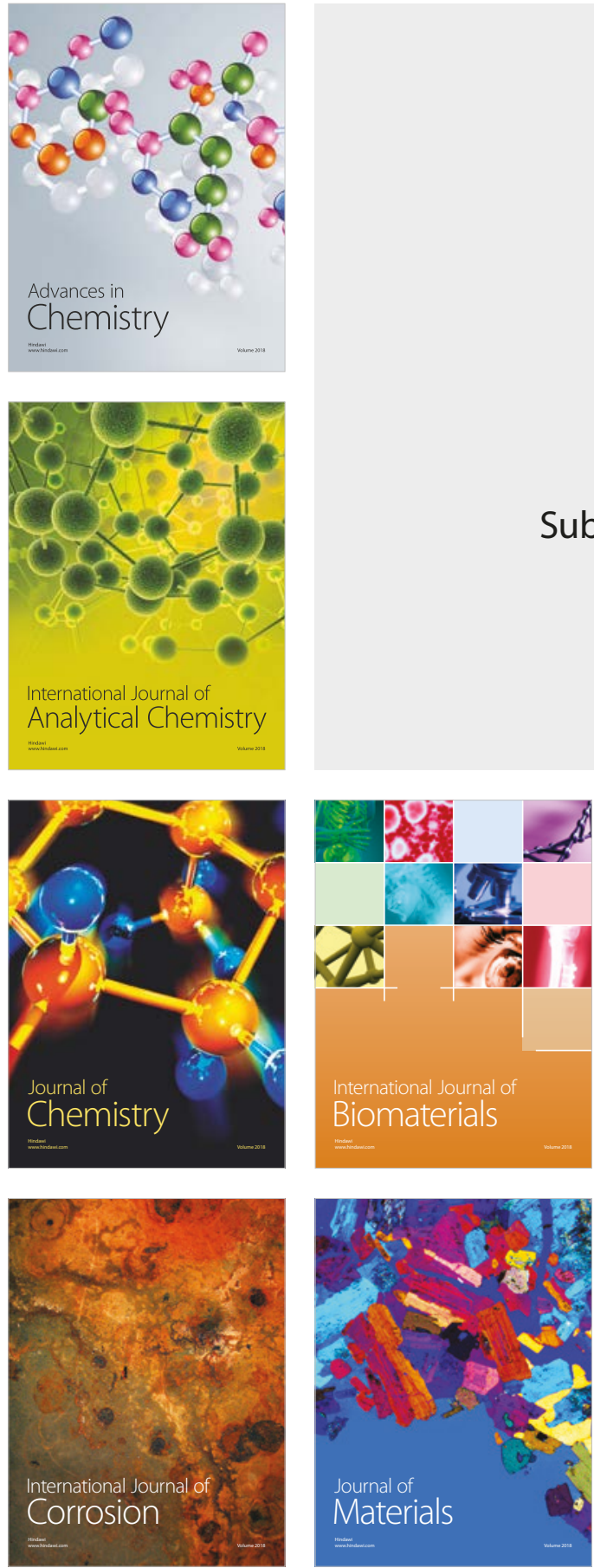

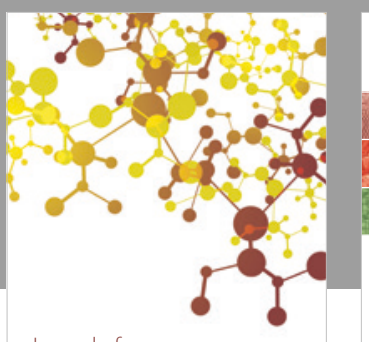

Journal of

Applied Chemistry
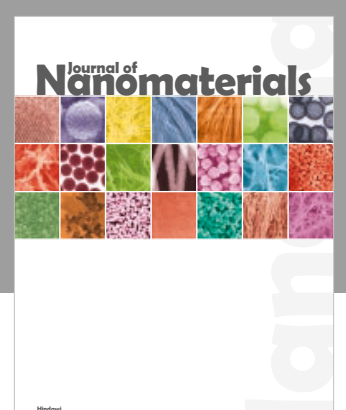

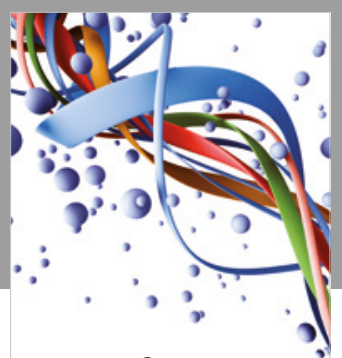

Scientifica

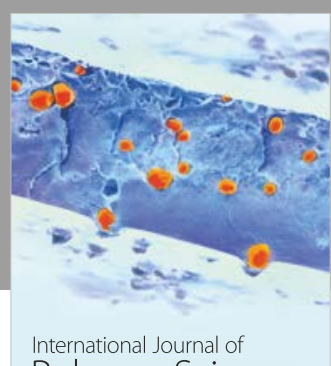

Polymer Science

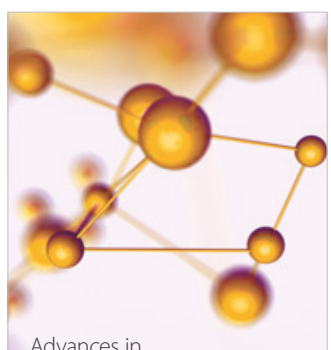

Physical Chemistry
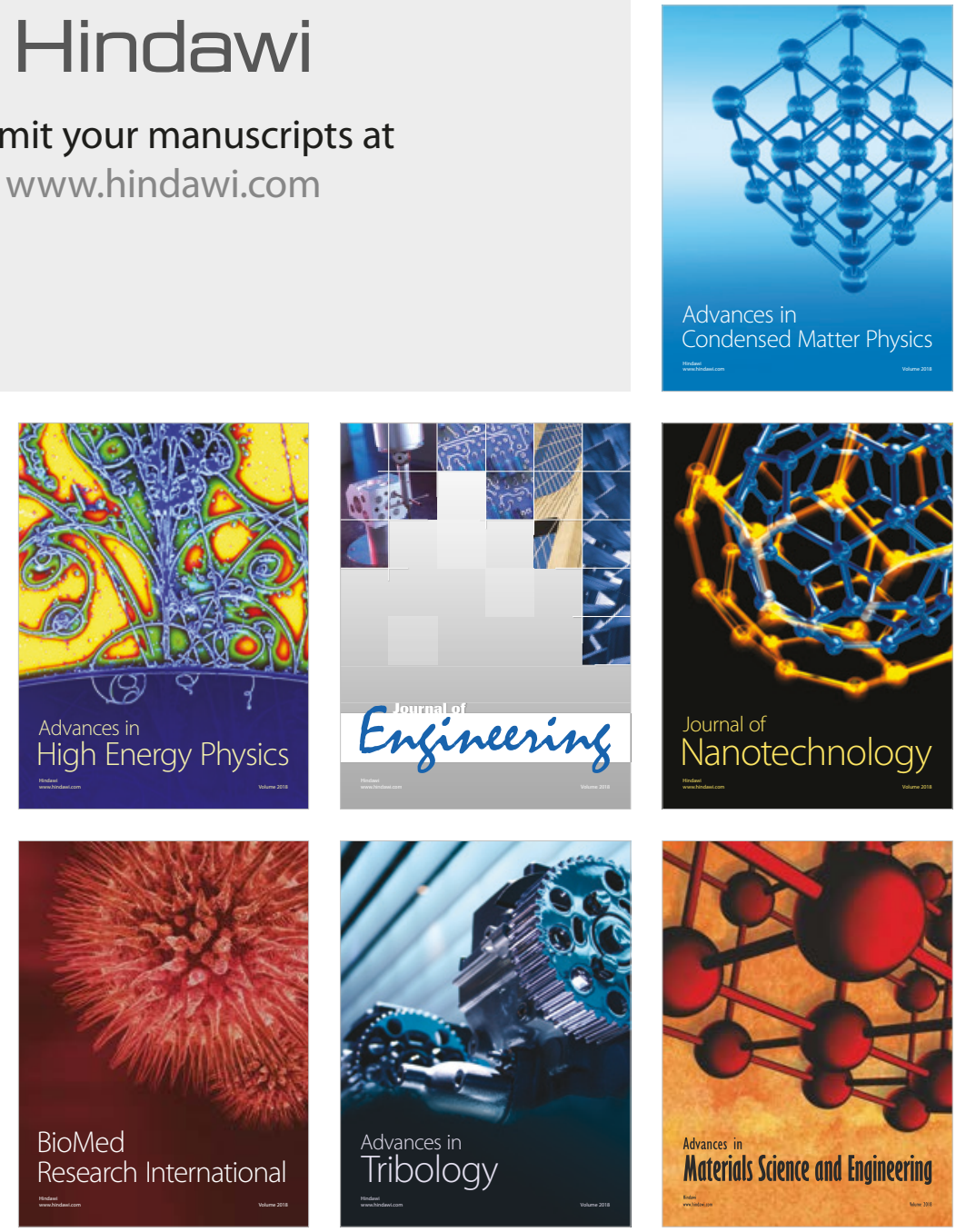